\title{
LAS HUELLAS DE LAS AVES EN LAS SOCIEDADES PASADAS: ANÁLLSIS SEMIÓTICO DE REPRESENTACIONES ORNITOMORFAS (FENÓMENO AGUADA, NOA)
}

\author{
THE TRACES OF THE BIRDS IN THE PAST SOCIETIES: A SEMIOTIC \\ ANALYSIS OF THE ORNITHOMORPHIC REPRESENTATIONS DURING THE \\ 'AGUADA' PHENOMENON (NORTHWEST, ARGENTINA)
}

Pablo Flores ${ }^{A}$ \& María Belén Velárdez Fresia

En este artículo se presenta el estudio de una selección de representaciones ornitomorfas sobre diferentes soportes materiales correspondientes al fenómeno Aguada en el NOA. La identificación taxonómica de especies mediante rasgos anatómicos, reveló una amplia variedad de aves tales como Falconiformes, Ara sp., Cyanoliseus patagonus, Asio stygius y Rhampastos toco. Nuestro análisis, desde una metodología semiótica, permitió entender las representaciones como posibles manifestaciones de la vida cotidiana y ritual de personas que incluían a las aves como constituyentes de su mundo social, interaccionando y construyendo prácticas y creencias derivadas de dicho vínculo.

Palabras clave: representaciones ornitomorfas, aves, Aguada, semiótica, agencia, Noroeste Argentino.

This paper presents a preliminary interpretation, using semiotic analysis, of ornithomorphic representations found on a variety of material supports corresponding to the "Aguada" phenomenon in Northwest Argentina. The taxonomic identification of species based on anatomical features revealed a wide variety of birds such as the Falconiforms Ara sp., Cyanoliseus patagonus, Asio stygius and Rhampastos toco. We propose that these ornithomorphic representations may be seen as expressions of the everyday and ritual lives of a people for whom birds were a fundamental part of the social sphere, with interactions, beliefs and practices constructed on the basis of their relation to these animals.

Keywords: ornithomorphic representations, birds, Aguada, semiotic, agency, Northwest Argentina.

\section{INTRODUCCIÓN}

En el presente trabajo se aborda la relación ave/humano en las sociedades del Noroeste Argentino (NOA) durante el denominado fenómeno Aguada (sensu Gordillo et al. 2000). Nos referimos a la conformación de un modo de experimentar el mundo, donde la conciencia social respecto de lo no humano en interacción con lo humano genera nuevas prácticas sociales que se nutren de esta significación. Proponemos acceder a este proceso de interacción ave/humano mediante el análisis de representaciones ornitomorfas provenientes de diferentes sitios arqueológicos y colecciones museográficas, correspondientes a lo que en la bibliografía se conoce como "cultura Aguada" o "fenómeno Aguada". El análisis consiste en la identificación taxonómica de las aves representadas mediante rasgos anatómicos distintivos por el artesano. Logrando dicha identificación y conjugándola con la funcionalidad del objeto mismo que contiene las representaciones, se abren posibilidades de interpretación con respecto a nuestra cuestión principal: ¿qué rol jugaron las aves en dicha sociedad?, ¿de qué

A Pablo Flores, Instituto de Arqueología y Museo (IAM) - Universidad Nacional de Tucumán/Centro de Rehabilitación de Aves Rapaces (CERAR), Reserva Experimental Horco Molle (REHM) - UNT, Caseros 2238 - Interno “C”, Salta Capital, Salta, Argentina. CP: A4400ACD, E-mail: flores.pablo31@gmail.com

B María Belén Velárdez, Instituto de Arqueología y Museo (IAM) - Universidad Nacional de Tucumán (UNT)/Centro de Rehabilitación de Aves Rapaces (CERAR), Reserva Experimental Horco Molle (венм) - unT, Muñecas 146, Tafí Viejo, Tucumán, Argentina. CP: T4103EID, E-mail: belenvfresia@outlook.com.ar

Recibido: agosto 2016. Aceptado: enero 2017. 
manera y a través de qué prácticas se integraron en su cosmovisión? Para responder, recurrimos a los postulados de la semiótica de la imagen de Magariños de Morentín (2008), como bases para el análisis iconográfico que se plantea en este trabajo.

Estas interrogantes fueron poco atendidas en la arqueología del NOA, desestimando el potencial de esta área de investigación. Es de nuestro interés proponer un acercamiento teórico-metodológico al arte precolombino Aguada, mediante la identificación taxonómica de las figuras de aves y un posterior análisis semiótico asociado a ellas. De esta manera podremos dar los primeros pasos para comprender el rol de las aves en la vida social de un grupo.

\section{DEFINIENDO UN MARCO SOCIAL}

Aguada ha sido objeto de estudio de la arqueología desde fines del siglo xix. En los últimos sesenta años, se definió como una entidad agro-alfarera en función de un estilo cerámico. El primero en asignarle nombre fue A. Rex González (1964), quien la denominó "cultura Aguada”. Luego, un variado grupo de autores (Pérez Gollán 1991, Tartusi \& Núñez Regueiro 2002, Laguens 2004, entre otros) realizaron aportes y críticas a esta primera definición.

Algunos, como Pérez Gollán (2000), Gordillo (2004) y Laguens (2004) consideran a Aguada como un proceso de complejidad creciente que llevó al desarrollo de desigualdades sociales basadas en la diferenciación de estatus o jerarquías. Esto dio origen a obras de irrigación y campos de cultivo de gran extensión, así como a la arquitectura monumental, lo que, sumado a otras evidencias, permite plantear una integración del culto a nivel panandino (Pérez Gollán 2000, González 2004) e incluso la institucionalización del culto a cargo de determinados actores sociales. En este sentido, para Tartusi y Núñez Regueiro (1990) Aguada significó la expansión de una ideología que se inicia en el siglo vi DC en Campo del Pucará y migra hacia el valle de Ambato y las llanuras orientales por la sierra de Escaba.

Por otra parte, Cruz (2007) propone para las ocupaciones Aguada una sociedad heterárquica, en la que se acepta la complejidad social, pero sin implicar la institucionalización de las jerarquías. Delfino (2005) adhiere a la postura de Cruz, y deduce/arguye para Laguna Blanca, sector donde también fue hallada cerámica Aguada, una forma comunal de ejercicio del poder. El autor está interesado en el rol de Laguna Blanca como articuladora de canales de intercambio durante el fenómeno.

\section{DEFINIENDO AMBIENTES Y RECURSOS}

Lo que hoy se conoce como Aguada se expresó en una extensa área del Noroeste Argentino, articulando distintos nichos ecológicos: tierras altas, intermedias y bajas. Su presencia está documentada en el sur de Salta, Tucumán, Catamarca, La Rioja y el norte de San Juan. Su influencia alcanzó hasta zonas del norte árido de Chile, como San Pedro de Atacama (Berenguer 1984, Llagostera 1995, Ataliva 2000).

La mayor concentración de sitios considerados Aguada se encuentra en regiones de valles y quebradas. Allí, la vegetación se acota a xerófilas, cactáceas, arbustos y bosques de chañares y algarrobo en las terrazas cercanas a los cauces fluviales. Actualmente, la fauna está compuesta por loros, cóndores, suris, zorros, roedores, pumas y guanacos (Pontussi et al. 1995). En aquel momento, habitar estos espacios incluyó, a menudo, el cultivo de especies como Zea mays, tubérculos (Solanum sp.), poroto (Phaseolus sp.) y cucurbitáceas (Cucurbita sp.), entre otras (Oliszeswki 2004).

En las yungas se han identificado sitios considerados Aguada en las inmediaciones del dique Escaba (Pantorrilla \& Núñez Regueiro 2006), el piedemonte oriental de las sierras del Aconquija (Manasse 2000, Miguez et al. 2013, Nasif \& Miguez 2014) y en los faldeos orientales de la sierra del Ancasti (Nazar et al. 2014). Las yungas ofrecen abundantes recursos cárnicos, como jabalíes, pecaríes y tapires, y vegetales tales como cebil, tipa, tarco, pacará, etcétera (Pontussi et al. 1995, Canevari \& Vaccaro 2007).

En la puna catamarqueña, los grupos que habitaron la zona contaron con una vegetación acotada a plantas arbustivas y cactáceas o vegas de altura ricas en pasturas. Entre las especies cultivables se destacan la papa (Solanum tuberosum), oca (Oxalis tuberosa) y quinoa (Chenopodium quinoa) (Babot 2016). La fauna está representada por una gran variedad de aves, como el cóndor, el choique, los flamencos andinos y los patos puneños; y mamíferos, principalmente roedores, zorros, pumas, tarucas, vicuñas y guanacos (Canevari \& Vaccaro 2007, Narosky \& Izurieta 2010). 


\section{ESTADO DE LA CUESTIÓN}

Los estudios de la iconografía Aguada se han focalizado en un repertorio caracterizado por la presencia de figuras felínicas y antropomorfas, siendo estos motivos los más recurrentes. La presencia de representaciones ornitomorfas es reconocida, pero han sido relegadas a la simple mención o a estudios cuantitativos (Kusch 1991, González 1998). Sin embargo, durante el fenómeno Aguada, las aves aparecen representadas de diversas maneras y en distintos soportes, con mayor o menor grado de detalle y recurrencia.

En la bibliografía encontramos un gran repertorio iconográfico y objetos mobiliarios, siendo el felino la figura clave en la mayoría de ellos. No obstante, también se incluyen numerosas referencias al reconocimiento de aves. Sitios con arte rupestre, como los de la sierra del Ancasti, presentan varias representaciones ornitomorfas (Nazar et al. 2012 y 2014). En este soporte material, las figuras por lo general no parecen conformar escenas, sino más bien se presentan aisladas.

En la cerámica es donde se encuentra la mayor riqueza y detalle de las imágenes, así como variedad de las mismas, tal como se ha puesto de manifiesto en el análisis que Elsa Montes hace en el libro de Rex González (1998). En este soporte, las aves aparecen de manera independiente o como parte de otros personajes. Tal es el caso de un jaguar de cerámica Portezuelo (Kusch 2000: lámina 1).

En metal, Luis González (2002) hizo un relevamiento de placas Aguada, entre las cuales cuatro poseen representaciones ornitomorfas (González 2002: figs. 1, 3 a y b, 9). Si bien no se realizó una interpretación de las figuras, se reconoce su presencia y se otorga un alto valor simbólico a estos objetos. González sugiere que, por su alta inversión de trabajo, conocimiento técnico, organización de la producción y amplia distribución surandina, se trataría de objetos suntuarios a través de los cuales los chamanes transmitían un mensaje religioso. A la vez, propone al chamán como metalurgista, lo que acrecentaría su poder al sumar conocimiento esotérico y técnico, ambos necesarios para divulgar en el bronce los principios y símbolos de los órdenes cósmico y social. Si bien no se detiene en la interpretación de la iconografía, reconoce la composición de la placa en su totalidad como parte fundamental de la cosmovisión de dicha sociedad, en la cual se encuentra representada el ave, como hemos visto.
En la piedra, contamos con los ejemplares presentes en este trabajo extraídos del libro de Rex González (1977), solo descritos por el autor. En hueso, aunque no hallamos la representación formal de un ave, la encontramos en el uso de partes esqueléticas de falcónidos en el armazón de una flauta en un contexto claramente ritual (Miguez et al. 2013). Las aves también aparecen representadas mediante sus plumas en ofrendas, como las de la cueva Inca Viejo, en la puna de Salta (López et al. 2015) y en el arte rupestre, cuando se observan tocados claramente asociables a adornos cefálicos plumarios (Gordillo et al. 2000). Sin embargo, a pesar de contar con una vasta presencia de aves en el repertorio Aguada, su intento por una interpretación más allá de la descripción ha resultado totalmente nulo y, en algunos casos, la identificación de especies ha sido errónea.

\section{Desde la semiótica a la imagen}

Las investigaciones arqueológicas muestran que, para los siglos VI-XI, en el NOA se incorporaron ciertas creencias y rituales que se manifestaron a nivel de superestructura (Tartusi \& Núñez Regueiro 2002), en lo que se conoce como fenómeno Aguada. Partiendo de allí, se estudiará la significación de las representaciones ornitomorfas, entendidas como signos, sensu Pierce (en Preucel 2006), de un fenómeno social, de acuerdo con los postulados que Magariños de Morentín (2008) establece para la semiótica icónica o "semiótica de la imagen material visual". De Morentín afirma que "la semiótica es el conjunto de conceptos y operaciones destinados a explicar cómo y por qué un determinado fenómeno adquiere, en una determinada sociedad y en un determinado momento histórico, una significación específica y cuál sea esta, cómo se la comunica y cuáles son sus posibilidades de transformación" (Magariños de Morentín 2008:1)1. Según este autor, una imagen material visual (IMV) es un tipo de percepción visual considerada como representación (figura), destinada a la configuración de una forma mental, para la valoración de un perceptor. Se la denomina material por la necesidad de un soporte físico para admitirla como punto de partida para un análisis semiótico.

Uno de los componentes básicos de la IMv son los "atractores", conjunto de formas almacenadas por repetición y fijación en nuestra memoria visual y que se encuentran disponibles para ser contrastadas con formas percibidas ocasionalmente, permitiendo identificar 
(o no) diferentes variantes del mismo. El autor define tres tipos de atractores, dependiendo de la forma de percepción de las IMV, donde se establece una relación entre atractores y signos indiciales: ${ }^{2}$

- Abstractivo: de naturaleza cualitativa (sensaciones), sin elementos figurativos ni simbólicos en su composición.

- Existencial: refiere a un existente, son imágenes figurativas de un objeto. Las diferentes imágenes mentales que un perceptor puede tener sobre un perro se activan al ver un individuo con cuatro patas, cola, pelos y comportamiento, coincidentes con imágenes previas de lo que categorizamos como perro. Cuando se activa un atractor existencial en nuestra cabeza, no se activan necesariamente imágenes del objeto real percibido (podemos no haberlo percibido antes), sino imágenes de aquellos rasgos que conforman al mismo: si es la primera vez que se percibe una llama, se pueden activar atractores de un animal diferente como las patas del carnero, su hocico, etcétera.

- Simbólico: aparecen organizados en un sistema. Alude a leyes tácitas y preexistentes en la sociedad, que nos permiten descubrir aquello que representa la IMv. Implica no solo pura experiencia perceptual, sino también existencial, inmersa en el marco social que genera los significados.

Magariños de Morentín (2008) clasifica las IMV en plástica, figurativa y conceptual. Nuestro trabajo centrará su atención en la IMV figurativa, aquella en que la propuesta visual del productor se establece como la sustituta de una imagen perceptual del intérprete. Su análisis y correlación con otros datos permitirá adentrarnos en la IMV conceptual, esto es, aquella en la que el intérprete percibe rasgos socialmente asignados para la comunicación de procesos conceptuales o hábitos y valores ideológicos y, consecuentemente, en su posible significación.

\section{Agencia: su rol en la construcción del signo}

Agencia es la capacidad que poseen los objetos y sujetos de generar efectos perceptibles como una acción, reacción o práctica social (Law 2008), es decir, la posibilidad de generar signos. Knappet (2008), a su vez, define la agencia como un proceso que se distribuye entre seres humanos y no humanos, los cuales pueden considerarse como atravesados por una red de nodos heterogéneos, cuyos efectos se observan sobre el comportamiento o la dinámica de las estructuras espacial y organizacional de los mismos. Visto a la luz de la semiótica peirceana, los significados también son establecidos según su dimensión práctica (consecuencias perceptibles) y negociados en contextos culturales habitados por actores sociales. Solo cuando observamos la agencia de un signo, podemos apreciar el significado del mismo en toda su dimensión. En este sentido, agencia y significado son equiparables.

Siguiendo la teoría de la agencia, la cultura material puede aceptarse como elemento activo dentro del ámbito social, permitiendo, facilitando o impidiendo la realización de empresas. Laguens \& Pazzarelli (2011) definen agencia como algo que tanto humanos como no humanos poseen. Consideran los objetos y a las personas como efectos de una serie de relaciones que implican una vinculación activa entre las partes, y en consecuencia, una tiene la capacidad de influir sobre la otra. Cualquier elemento que genere un efecto de relación o tenga un valor de significación es considerado un agente (Laguens \& Pazzarelli 2011).

Por tanto, si la agencia es la capacidad de producir efectos, también crea signos, ya que una acción o efecto es indicio de otra $y$, a la vez, punto de partida para otros signos. Prestar atención a la agencia es desandar caminos para acercarnos a los significados, entender qué se hizo es comprender cómo llegó a hacerse algo y aproximarnos poco a poco a sus motivos, construidos de signo en signo.

La materialidad ejerce agencia de diferentes maneras, dando lugar a comportamientos, acciones y prácticas específicas que conservan, transforman y transmiten rasgos de determinada visión de mundo. Esta agencia solo tiene lugar en relación con los otros, creando una trama particular, cuyo resultado derivado es la configuración de una ontología humana, integradora de los interactuantes, y es a ella a la que pretendemos acceder.

Considerando el objetivo del trabajo, prestaremos atención a la distribución de las aves identificadas y su comportamiento, para determinar las relaciones que establecieron con los grupos humanos que habitaron la zona. Mediante las representaciones ornitomorfas que estas poblaciones dejaron, podemos dilucidar algunos elementos fundamentales de la concepción social respecto de las aves, así como del vínculo entre ambas, lo que implica acceder a algunos aspectos de su cosmología. 


\section{METODOLOGÍA}

El relevamiento de representaciones ornitomorfas atribuidas al fenómeno Aguada se llevó a cabo mediante la consulta bibliográfica respectiva y la base de datos de la colección arqueológica del Instituto de Arqueología y Museo (Tucumán). Para la sistematización de la información se utilizaron planillas de formato Excell, y las variables consideradas fueron:

- ubicación de la pieza: colección, número de pieza (si es que tuviera asignado uno); procedencia (siempre que la hubiere) y referencia bibliográfica;

- materia prima: piedra, hueso, metal, grabados o motivos rupestres y cerámica;

- respecto de la cerámica: forma, tipología y color;

- diseño en cerámica: pintado, grabado o inciso;

- motivo ornitomorfo: si es figurativo, abstracto, cantidad, ubicación en la pieza, ubicación en relación con otros motivos, y tipo de simetría;

- motivos asociados: humano, felino, ofidio, felino humanizado, humano felinizado, gométricos, draconiformes, y otros.

La elección de este tipo de soporte virtual como base de datos se debió a su accesibilidad, su interfaz de manejo sencillo, la posibilidad de la utilización de filtros múltiples y la elaboración de gráficos de distribución. Como ya señalamos, las representaciones más consideradas en la arqueología corresponden a las del jaguar, cóndor o suri. No hay trabajos específicos de otro tipo de representaciones ornitomorfas que nos encuadren un marco en el cual proseguir. Por lo tanto, se tomó como criterio de selección de la muestra aquellas imágenes de aves cuyos rasgos anatómicos aparecieran representados de manera figurativa, las cuales consideramos adecuadas para la realización de una identificación taxonómica. No tuvimos acceso de manera directa a ninguno de los objetos que actuaron como soportes de las representaciones analizadas, pero sí a través de sus imágenes presentes en publicaciones, útiles para la observación de rasgos diagnósticos que permiten su clasificación (en algunos casos, las piezas fueron robadas). Las IMV analizadas fueron tomadas principalmente de Rex González $(1977,1998)$ y, en menor medida, de Korstanje (1988) y Pérez Gollán (1994). La determinación taxonómica fue resultado de la consulta de bibliografía ornitológica y la observación del comportamiento de aves en el CERAR:
La determinación de atractores abstractivos, existenciales y simbólicos (Tabla 1), supuso un proceso de observación, ordenamiento e identificación de atributos importantes para interpretar las imv. En cada caso, los atractores permitieron:

- Definir las cualidades consideradas por el artista a la hora de elaborar la IMv, que forman parte del contenido sígnico de la misma. Esto ofrece indicios de las elecciones o decisiones técnicas tomadas dentro de un contexto social específico (abstractivos).

- Aislar rasgos que nos remiten a existentes reales, en este caso aves, siendo estos un apoyo para la identificación taxonómica (existenciales).

- Sugerir lo que las imágenes podrían representar de acuerdo a aquellos supuestos tácitos de la sociedad Aguada (simbólicos). Si bien no conocemos todo el sistema que organiza y da sentido simbólico a estas imágenes, planteamos que es posible inferirlo a partir de la red de relaciones que incluye a dichas aves identificadas (sus comportamientos, habilidades y características asociados a los atractores existenciales y abstractivos), al soporte material y al contexto social específico definido a través de la lectura de bibliografía etnográfica y arqueológica.

Combinando todos estos pasos, pudimos acceder a la posible IMv conceptual que condensa el significado de cada una de las representaciones ornitomorfas analizadas en este trabajo.

\section{Resultados}

Se registraron 44 piezas con motivos ornitomorfos, de las cuales: 28 se encuentran en cerámica (64\%), 7 en metal (16\%), 4 en piedra (9\%), 4 en grabados o motivos rupestres (9\%) y 1 en hueso (2\%). La determinación taxonómica, así como el análisis semiótico se efectuó sobre 3 artefactos de piedra (figs. 1-3) y 7 cerámicos (figs. 4-10).

La mayoría de la información utilizada para la descripción taxonómica proviene de Contino (1982), Rodríguez Mata et al. (2006) y Narosky \& Yzurieta (2010). A continuación, describiremos los grupos identificados en el análisis (género, orden o familia) y luego la especie identificada. 
Tabla 1. Cuadro 1. Análisis semiótico e identificación taxonómica. Table 1. Cuadro 1. Análisis semiótico e identificación taxonómica.

\begin{tabular}{|c|c|c|c|c|c|}
\hline \multirow{2}{*}{ 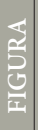 } & & \multicolumn{3}{|c|}{ DESCRIPCIÓN DE LA PIEZA } & \multirow{2}{*}{$\begin{array}{l}\text { IDENTIFICACIÓN } \\
\text { TAXONÓMICA }\end{array}$} \\
\hline & & ABSTRACTIVOS & EXISTENCIALES & SIMBÓLICOS & \\
\hline 1 & $\begin{array}{l}\text { Tortero o cuenta en piedra. Alto: } 4 \mathrm{~cm} / \\
\text { diámetro: } 1 \mathrm{~cm} \text {. Procedencia: Catamarca. } \\
\text { La figura se encuentra de perfil dividida en dos } \\
\text { claros sectores: cuerpo y cabeza. Sobresalen su } \\
\text { pico, ojo y dos protuberancias superiores. En el } \\
\text { cuerpo se distinguen las alas pegadas al mismo. }\end{array}$ & $\begin{array}{l}\text { Color y } \\
\text { textura de } \\
\text { la roca. }\end{array}$ & $\begin{array}{l}\text { Pico, alas, ojo, } \\
\text { cuerpo, ave, loro, } \\
\text { disco facial, búho. }\end{array}$ & $\begin{array}{l}\text { Visibilidad, } \\
\text { oscuridad. }\end{array}$ & $\begin{array}{l}\text { Asio stygius } \\
\text { (especie) }\end{array}$ \\
\hline 2 & $\begin{array}{l}\text { Tortero o cuenta en piedra. Alto: } 2,1 \mathrm{~cm} / \\
\text { diámetro: } 1,7 \mathrm{~cm} \text {. Procedencia: Catamarca, } \\
\text { La puntilla, Belén. Se observa al ave en actitud } \\
\text { defensiva, con la cabeza agachada y las alas } \\
\text { cubriendo sus laterales del cuerpo. Garras y } \\
\text { pico claramente representados. }\end{array}$ & $\begin{array}{l}\text { Color y } \\
\text { textura de } \\
\text { la roca. }\end{array}$ & $\begin{array}{l}\text { Pico, alas, ojo, } \\
\text { garras, ave, } \\
\text { rapaz, comida. }\end{array}$ & $\begin{array}{l}\text { Defensa, } \\
\text { alerta, } \\
\text { agresividad. }\end{array}$ & $\begin{array}{l}\text { Falconiforme } \\
\text { (Orden) }\end{array}$ \\
\hline 3 & $\begin{array}{l}\text { Recipiente de piedra con asa en forma de } \\
\text { cuello y cabeza de un ave y motivos grabados. } \\
\text { Sin procedencia. Alto: } 14,5 \mathrm{~cm} / \text { largo: } 22 \mathrm{~cm} \text {. } \\
\text { El cuenco actúa como representante del } \\
\text { cuerpo del ave. }\end{array}$ & $\begin{array}{l}\text { Color y } \\
\text { textura de } \\
\text { la roca. }\end{array}$ & $\begin{array}{l}\text { Pico, cuello largo, } \\
\text { agua, ojo, lluvia, suri. }\end{array}$ & $\begin{array}{c}\text { Profundidad, } \\
\text { abundancia. }\end{array}$ & $\begin{array}{l}\text { Rheidae } \\
\text { (Familia) }\end{array}$ \\
\hline 4 & $\begin{array}{l}\text { Motivo ornitomorfo de vasija Aguada Pintado. } \\
\text { Procedencia: La Falda, Belén, Catamarca. } \\
\text { Contexto: poseía un párvulo en su interior. } \\
\text { Figura ornitomorfa de perfil. }\end{array}$ & $\begin{array}{l}\text { Colores de la } \\
\text { vasija y de los } \\
\text { pigmentos del } \\
\text { motivo. }\end{array}$ & $\begin{array}{l}\text { Pico largo, ojos grandes, } \\
\text { bulto en el cuello, patas } \\
\text { largas, alas extendidas, } \\
\text { cola grande. }\end{array}$ & Movimiento. & $\begin{array}{l}\text { Rhea } \\
\text { pennata } \\
\text { (Especie) }\end{array}$ \\
\hline 5 & $\begin{array}{l}\text { Imagen antropofelínica y ornitomorfa en } \\
\text { puco Ambato negro grabado. Procedencia: } \\
\text { Valle Viejo, Catamarca. Se observa un cóndor } \\
\text { a la izquierda de un felino antropomorfizado. }\end{array}$ & $\begin{array}{l}\text { Color del } \\
\text { puco y } \\
\text { textura de las } \\
\text { incisiones. }\end{array}$ & $\begin{array}{l}\text { Pico, cresta, pata } \\
\text { anisodáctila, cola, alas, } \\
\text { cuello desnudo. }\end{array}$ & $\begin{array}{l}\text { Vuelo, } \\
\text { sapiencia, } \\
\text { grandeza. }\end{array}$ & $\begin{array}{c}\text { Vultur } \\
\text { gryphuso } \\
\text { Sarcoramphus } \\
\text { papa(Especie) }\end{array}$ \\
\hline 6 & $\begin{array}{l}\text { Sin Procedencia. Se observan dos aves en } \\
\text { igual posición con alas extendidas y la cabeza } \\
\text { mirando hacia los laterales en un panel de } \\
\text { vaso Aguada Gris Grabado. }\end{array}$ & $\begin{array}{l}\text { Color del vaso } \\
\text { y textura de } \\
\text { las incisiones. }\end{array}$ & $\begin{array}{l}\text { Pico ganchudo, periocular, } \\
\text { ojo, mejilla, alas, cola, } \\
\text { guacamayo. }\end{array}$ & $\begin{array}{l}\text { Vuelo, viaje, } \\
\text { altura, } \\
\text { intensidad. }\end{array}$ & $\begin{array}{l}\text { Arasp. } \\
\text { (Género) }\end{array}$ \\
\hline 7 & $\begin{array}{l}\text { Puco estilo Hualfín Gris Grabado. Cementerio } \\
\text { Orilla Norte de la Aguada, La Rioja. Se } \\
\text { observan representaciones de psitácidos en } \\
\text { actitud de caminar en la parte exterior del puco. }\end{array}$ & $\begin{array}{l}\text { Color del } \\
\text { puco y } \\
\text { textura de las } \\
\text { incisiones. }\end{array}$ & $\begin{array}{l}\text { Pico ganchudo, patas } \\
\text { zigodáctilas, cola larga, } \\
\text { alas, loro, plumas } \\
\text { escamadas, barranca. }\end{array}$ & $\begin{array}{l}\text { Vuelo, viaje, } \\
\text { altura, sonido } \\
\text { fuerte. }\end{array}$ & $\begin{array}{l}\text { Cyanoliseus } \\
\text { patagonus } \\
\text { (Especie) }\end{array}$ \\
\hline 8 & $\begin{array}{l}\text { Vasija de forma simple ovoide invertida Aguada } \\
\text { Pintado con gran figura de ave. Procedencia: } \\
\text { Aguada Meriodinal. Se observa un ave con } \\
\text { gran pico y una protuberancia de grandes } \\
\text { dimensiones en el cuello. Se la dibuja de perfil. }\end{array}$ & $\begin{array}{l}\text { Color de } \\
\text { la vasija y de } \\
\text { los pigmentos } \\
\text { negros. }\end{array}$ & $\begin{array}{l}\text { Pico largo, patas } \\
\text { flexionadas hacia atrás, alas, } \\
\text { protuberancia en el cuello, } \\
\text { cuello largo, ojo, ave, pico } \\
\text { curvo, tucán, jabiru. }\end{array}$ & Fuerza & $\begin{array}{l}\text { Ramphastos } \\
\text { toco } \\
\text { (Especie) }\end{array}$ \\
\hline 9 & $\begin{array}{l}\text { Vaso de cerámica Aguada Pintado en negro } \\
\text { y rojo sobre rojizo-amarillo. Altura: } 17,1 \mathrm{~cm} / \\
\text { diámetro máximo: } 12,3 \mathrm{~cm} \text {. Procedencia: } \\
\text { Aguada Septentrional. Antropomorfo } \\
\text { felinizado de frente, con dos discos en el } \\
\text { lugar de las orejas, donde se observan dos } \\
\text { representaciones ornitomorfas de pico largo. }\end{array}$ & $\begin{array}{l}\text { Colores del } \\
\text { vaso y de los } \\
\text { pigmentos } \\
\text { negro y rojizo. }\end{array}$ & $\begin{array}{l}\text { Pico largo, patas } \\
\text { zigodáctilas, alas, cola, } \\
\text { chaman, jaguar. }\end{array}$ & Vuelo, altura & $\begin{array}{l}\text { Ramphastos } \\
\text { toco } \\
\text { (Especie) }\end{array}$ \\
\hline
\end{tabular}




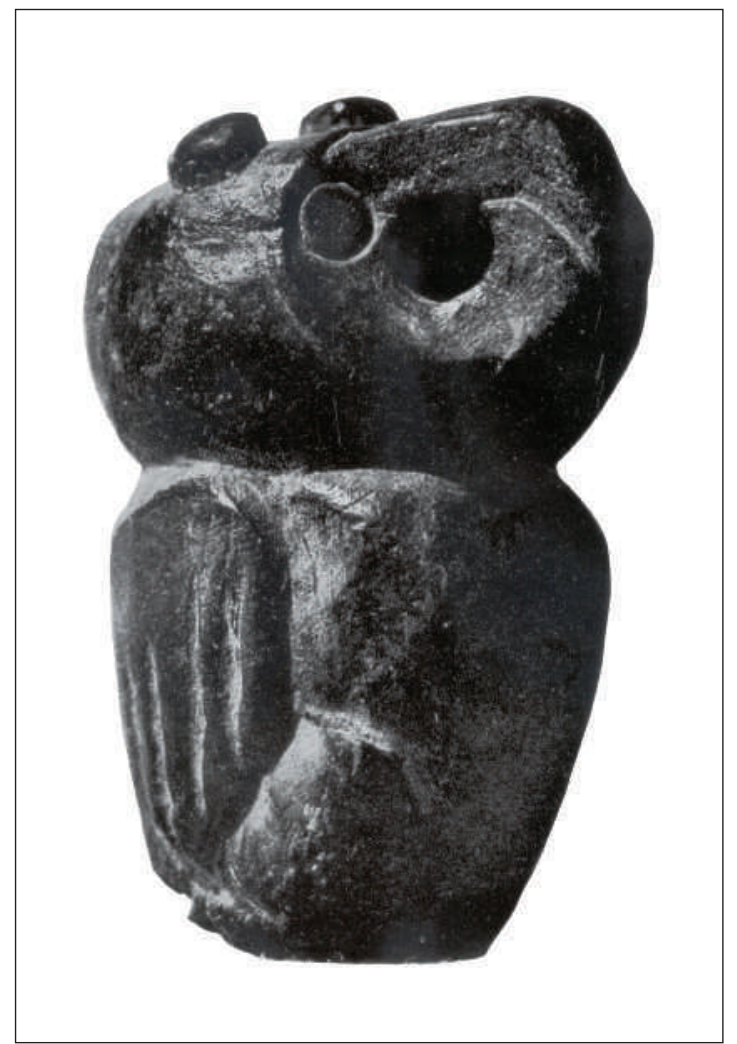

Figura 1. Cuenta de piedra en forma de ave (pieza robada). Colección Museo Adán Quiroga (en González 1977: fig. 230). Figure 1. Bird-shaped stone bead (item stolen), Museo Adán Quiroga Collection (in González 1977: fig. 230).

\section{Familia Strigidae}

Aves rapaces nocturnas. De vuelo silencioso, poseen ojos frontales y disco facial, pico curvo y corto, garras muy fuertes. Se alimentan de invertebrados o pequeños vertebrados. Se distinguió una especie.

Asio stygius (lechuzón negruzco): de color negruzco. Exhibe en su cabeza dos largos tufos de plumas negras que se confunden con "orejas" o "cuernos". Habita en selvas húmedas de montaña y en selvas lluviosas de tierras bajas.

Si bien esta figura puede confundirse con un psitácido por el pico ganchudo (puede deberse al orificio que lo atraviesa afectando sus dimensiones), la identificación del Asio stygius se basa principalmente en su morfología, ya que la imagen no presenta detalles con textura o división de sectores que indiquen algún cambio de plumaje o color. La figurilla posee un disco facial claramente circular donde se disponen el pico y

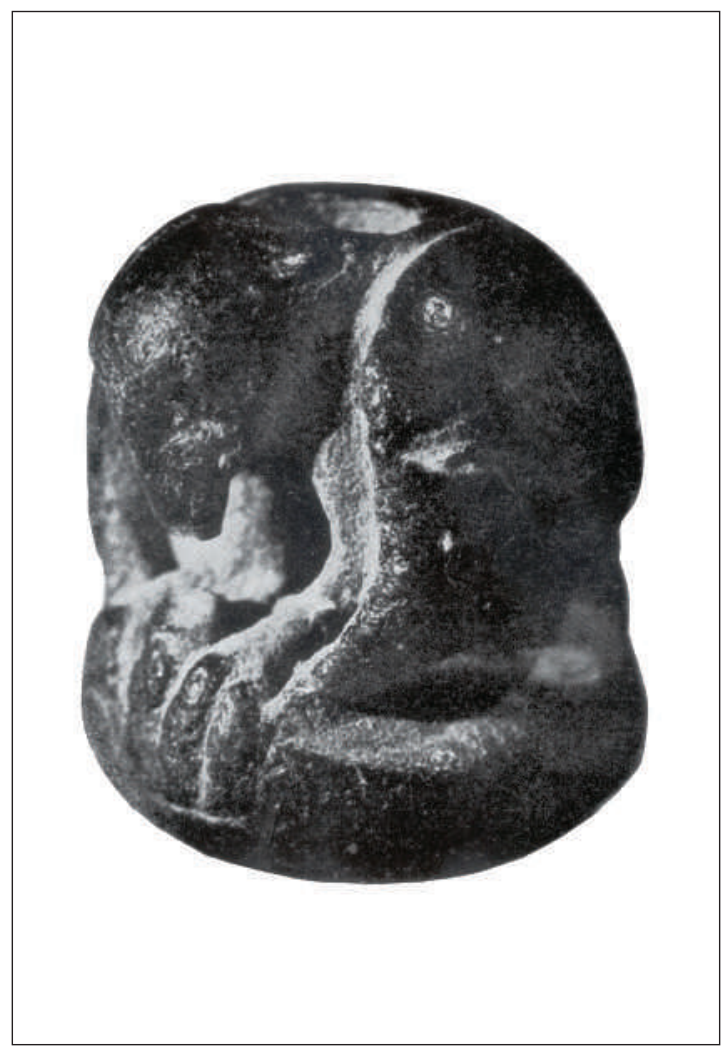

Figura 2. Tortero o cuenta de piedra en forma de rapaz (pieza robada). Colección Eduardo Curá (en González 1977: fig. 231). Figure 2. Raptor-shaped spindle whorl or bead (item stolen), Eduardo Curá Collection (in González 1977: fig. 231).

los ojos perfectamente circulares, muy cercanos entre sí, característica propia del orden Estrigiformes y de esta especie en particular. Las dos protuberancias que presenta la cuenta en la parte superior remiten a las plumas dispuestas a modo de "cuernos". Otro aspecto que cabe destacar es el color negruzco del ave, similar al de la materia prima en que se realizó la figurilla. La cola de esta ave es corta y casi no se diferencia del resto del cuerpo, probablemente por eso en la cuenta tampoco se encuentra representada.

\section{Orden Falconiformes}

Comprende todas las rapaces diurnas, poseen cuerpo fuerte y compacto, miembros robustos y cabeza más o menos redondeada, con un pico fuerte y cortante en forma de garfio. Son generalmente cazadoras. En el análisis no pudimos distinguir más allá del orden. 


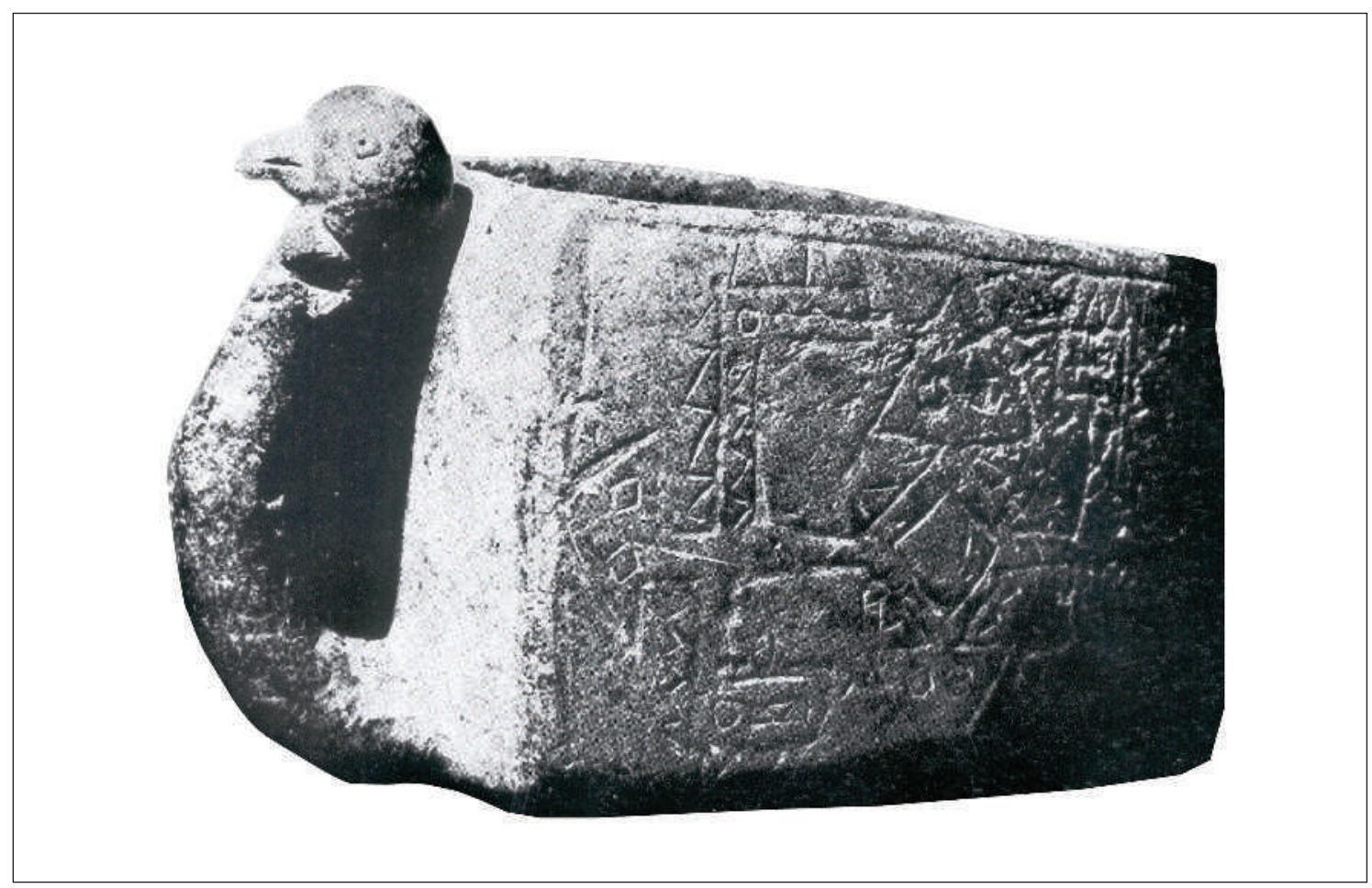

Figura 3. Recipiente de piedra ornitomorfo (pieza robada). Instituto de Arqueología y Museo (en González 1977: fig. 81). Figure 3. Ornithomorphic stone recipient (item stolen). Instituto de Arqueología y Museo (in González 1977: fig. 81).

Esta cuenta fue identificada recurriendo a rasgos anatómicos y datos etológicos. Sus garras afiladas y grandes, su pico largo y curvo, así como sus alas proporcionalmente grandes con respecto al cuerpo nos permiten sugerir que puede tratarse de un falconiforme. En la figurilla podemos observar sus garras firmemente sujetas a un objeto, sugiriendo una escena postcaza, donde el individuo protege la comida tapándola con sus alas ante la amenaza de otro oportunista, comportamiento común a todos los falconiformes (observado por los autores en un ejemplar de Spizaetus melanoleucus -águila viuda- en CERAR). La figura no nos muestra mayores detalles que permitan distinguir familia, género ni especie.

\section{Familia Rheidae}

Aves corredoras de gran tamaño, no aptas para el vuelo ( $\sin$ plumas rígidas). Viven en grupo, son polígamos. Poseen patas y cuello largos. Se distinguieron dos posibles especies.

Rhea americana (suri): plumaje negro y blanco, pico corto y recto. En el dorso predominan los colores negro, pardo y ocre entremezclados. Forman pequeños grupos. Anidan en campos abiertos con arbustos, los huevos son incubados por el macho, quien cuida los polluelos. Habitan en las llanuras chaqueñas, pampeanas y puneñas hasta los $2000 \mathrm{msnm}$.

Rhea pennata (suri cordillerano): semejante a Rhea americana salvo por su plumaje y tamaño. Alas color pardo con los extremos de las plumas notablemente manchadas de blanco. En el NOA se encuentran en planicies sobre los $4000 \mathrm{msnm}$.

En el vaso se representa un ave de cuello largo y corvo hacia arriba, pico recto y no muy prolongado tal como aparece en Rhea sp. No podemos diferenciarlos, ya que la única forma de identificarlos es a través de sus colores, dimensiones y hábitat, datos que no poseemos.

Posiblemente correspondiente a Rhea pennata. Posee patas largas y flexionadas en actitud de movimiento en conjunción con alas desplegadas, actitud común en estas aves para cierto tipo de situaciones: cortejo, desplazamiento, agresividad, etc. El pico no parece ser representativo de estas especies, ya que es largo y hacia abajo. El cuello aparece ancho y curvado 


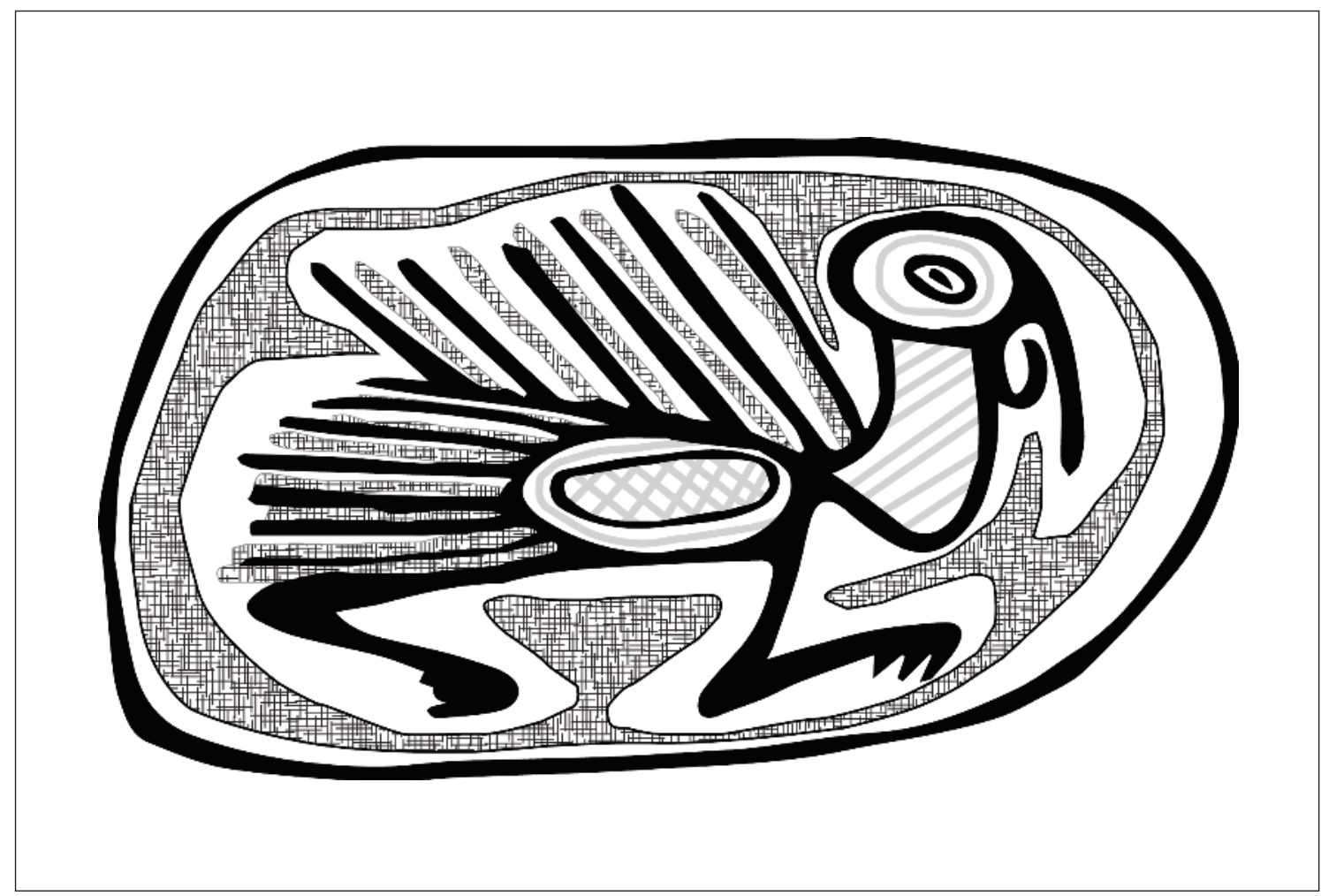

Figura 4. Motivo ornitomorfo de vasija Aguada Pintado. Colección Paz Posse, Instituto de Arqueología y Museo (Tucumán) Ma0079 (apud Korstanje 1988: 223). Figure 4. Bird motif on an Aguada Pintado vessel. Paz Posse Collection, Instituto de Arqueología y Museo (Tucumán) MA0079 (apud Korstanje 1988: 223).

similar al del choique, pero mucho más grueso. En su vientre se observa un diseño cuadriculado que recuerda al moteado que poseen estas aves en sus alas.

\section{Familia Cathartidae}

Aves carroñeras y solitarias. Alas largas y anchas con cabeza desnuda. Se distinguió una especie.

Vultur gryphus (cóndor): totalmente negro, excepto un collar que rodea el cuello y la parte superior de las alas, que son blancas. Cabeza y cuello desnudo. El macho posee cresta. Puede pasar los tres metros de envergadura alar. Se alimenta principalmente de carroña. Posee una amplia distribución en el NOA y los Andes, donde habita zonas de altura.

En esta imagen, el cóndor juega un rol importante en la composición; probablemente los diseños representados en su interior estén más asociados a la totalidad del panel que a detalles morfológicos de la especie. Entre los rasgos anatómicos por destacar y coincidentes con esta especie, observamos el pico largo con un maxilar superior más grande que el inferior, la cresta y la cola. Algunos de estos rasgos coinciden con Sarcoramphus papa (jote real), pero difiere del cóndor por su plumaje, hábitat y tamaño.

\section{Familia Psittacidae}

Los loros son muy inteligentes, llegando a compararse con delfines o chimpancés. El pico es fuerte, ganchudo y robusto. La mayoría presenta un periocular distinguible, son zigodáctilos. Anidan en cuevas, riscos, termiteros $\mathrm{u}$ oquedades de troncos y suelen formar parejas de por vida en colonias de diversos tamaños. La vida en comunidad es una de las principales catalizadoras del elaborado desarrollo de su repertorio vocal y capacidad de aprender nuevos vocablos (Del Valle 2008). Siguen los ciclos de floración y fructificación, visitan plantaciones y sembradíos. Se distinguieron una especie y un género. Para determinar taxonómicamente el género de estos 


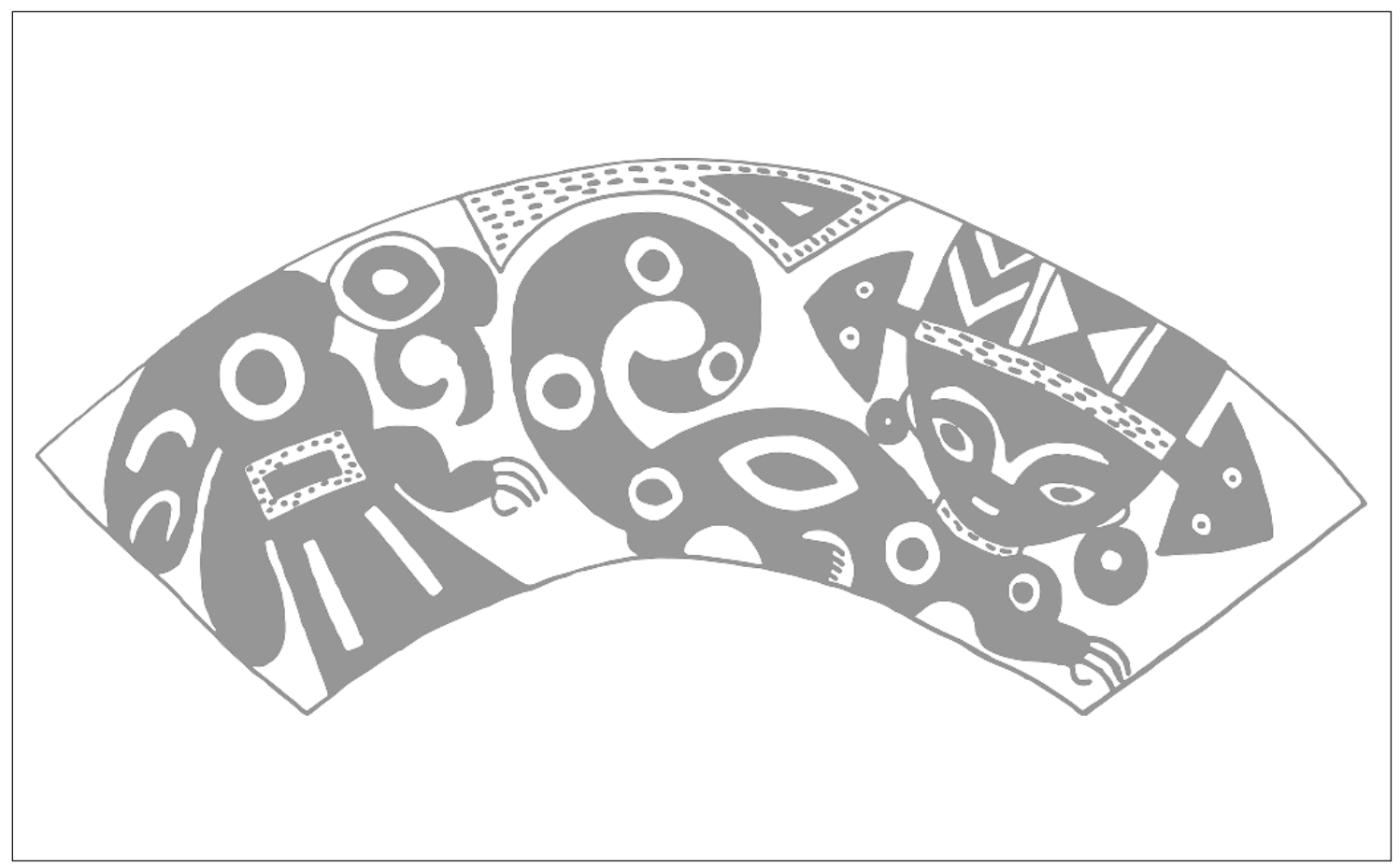

Figura 5. Motivo ornitomorfo y felino-antropomorfo. Colección Museo Adán Quiroga nº 284 (apud González 1998: fig. 141 ). Figure 5. Ornithomorphic motif and anthropomorphic feline. Museo Adán Quiroga Collection n 284 (apud González 1998: fig. 141).

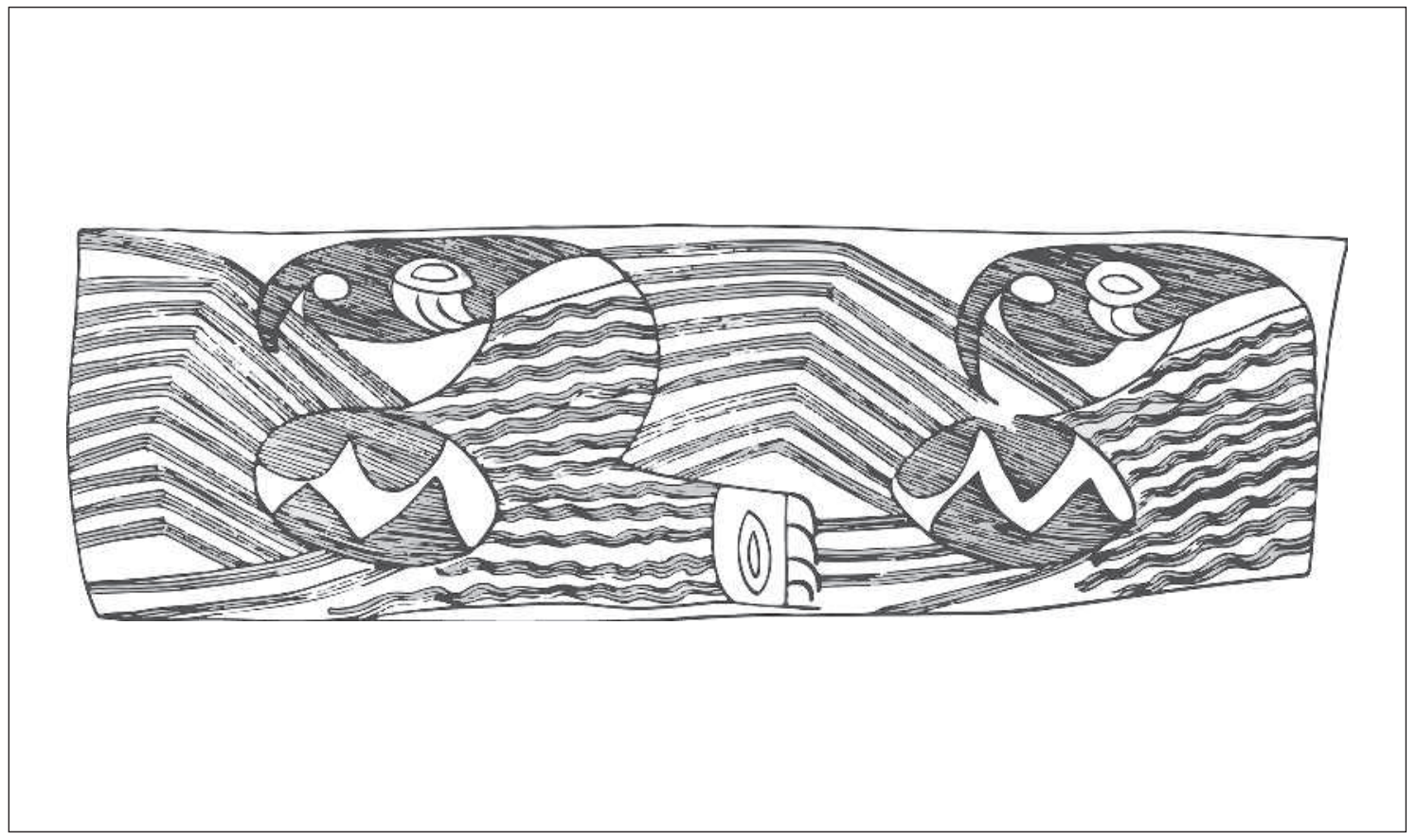

Figura 6. Estilizaciones ornitomorfas en un panel de vaso Aguada Gris Grabado. Colección Museo Incahuasi n 1984 (apud González 1977: fig 111). Figure 6. Stylized ornithomorphic figures on a panel of an Aguada Gris Grabado cup. Museo Incahuasi Collection $n^{\circ} 1984$ (apud González 1977: fig. 111). 
individuos debemos tener en cuenta los atributos variables de dicha familia: morfología, hábitat, adaptaciones a distintos ecosistemas, capacidades, comportamiento y sonidos (Ottalagano 2008). Como solo poseemos representada su forma, entonces nos basaremos principalmente en el primer aspecto mencionado. Tendremos en cuenta algunas características que actualmente se usan para diferenciarlos, como la ausencia o presencia de plumas en las mejillas, las dimensiones de la cola con respecto al cuerpo y su forma.

Cyanoliseus patagonus (loro barranquero): color olivo-pardusco, periocular blanco, vientre y rabadilla de amarillo intenso. Pico ganchudo y corto. Frente amplia. Se lo observa en grandes bandadas. Se alimentan de semillas y frutos como el chañar y algarrobo. Nidifica en huecos y cuevas hechos en barrancas y riscos. Habita en sabanas, estepas arbustivas, áreas andinas, tierras bajas áridas y praderas de matorrales montanos.

Género Ara: Son los gigantes de la familia Psittacidae. Espectacularmente coloridos, poseen picos enormes, colas muy largas y en punta. Se alimentan de insectos y bayas. Viven en los árboles. En algunas especies, la cara es de color blanco y surcada por finas plumas debajo de sus ojos.

Posible representación del género Ara. En la imagen podemos distinguir claramente diseños en sus mejillas que podrían corresponder con algunas especies del género, que se caracteriza por la ausencia de plumaje alrededor de sus ojos donde se ubican trazos lineales de pequeñas plumitas de colores contrastantes. Las alas aparecen ampliamente desplegadas y proporcionalmente más grandes con respecto al cuerpo. En cuanto a la cola, no aparece completamente dibujada, probablemente debido al espacio del que disponía el artista; sin embargo, las líneas que representarían la misma son continuas y pronunciadas hacia abajo, permitiéndonos inferir una mayor extensión que podría corresponderse con este tipo de aves de cola larga. Además, este género presenta picos más pronunciados en los que se destacaría una mayor proyección de la mandíbula superior sobre la inferior (Ottalagano 2008).

Esta misma imagen fue analizada e interpretada por A. Rex González (1998: 177) como un cóndor o águila. Igualmente, Elsa Montes considera que correspondería a un falcónido, por las líneas suboculares (González 1998: xxII), quizás basándose en los planteos de Yacovleff (1932) sobre la relación entre las líneas suboculares de los falcónidos y los lagrimones de las estatuillas del NOA.
En estas figuras se representa un ave similar a un psitácido. En cuanto al pico, no presenta una diferencia notable entre maxilar superior e inferior, descartando Ara sp. La cola dibujada es larga y de forma similar a la de Cyanoliseus patagonus. Esta imagen posee un periocular marcado y a la vez resaltante debido al efecto logrado por las incisiones en dirección diagonal que circunscriben al ojo. Esto puede observarse claramente en el Cyanoliseus patagonus, donde sus cobertoras verde oliva contrastan con su periocular blanco. En la composición se observa una segmentación en la región que representa garganta y cuello. Quizás estos sectores diferenciados por diseños incisos distintos estén refiriendo al cambio de coloración en el plumaje, como la observada en el ave (transición verde oliva en la cabeza a gris en cuello, garganta y espalda). Otro aspecto destacable en esta especie es la frente sobresaliente.

\section{Familia Ramphastidae}

Los tucanes son aves arborícolas y bastante ruidosas. Poseen un pico muy grande y colorido, las alas son cortas y poseen una cola larga. Su vuelo es alto y recto. Se distinguió una especie.

Ramphastos toco (tucán): negro en casi su totalidad. Una gran mancha blanca cubre el cuello y parte del pecho, cobertoras caudales superiores blancas y cobertoras caudales inferiores rojas. Pico voluminoso, con colores anaranjados. El extremo de la mandíbula superior presenta una amplia mancha oval negra. La región alrededor de sus ojos es de color anaranjado y se encuentra desnuda. Habita selvas húmedas formando pequeñas bandadas. Puede alimentarse de frutos, flores, huevos, ratones y hasta murciélagos.

En esta imagen se observa un ave con pico largo y corvo hacia adentro. Presenta una protuberancia en el cuello que podría corresponderse con los sacos aéreos subcutáneos que posee Jabiru mycteria (jabirú). Sin embargo, el pico de esta ave es curvado hacia arriba, por esta razón asociamos la imagen más a un tucán que a esta cigüeña.

En esta imagen las aves presentan un pico largo y curvado hacia dentro, unos grandes ojos circulares y una cola de forma rectangular, característicos de Ramphastos toco. 


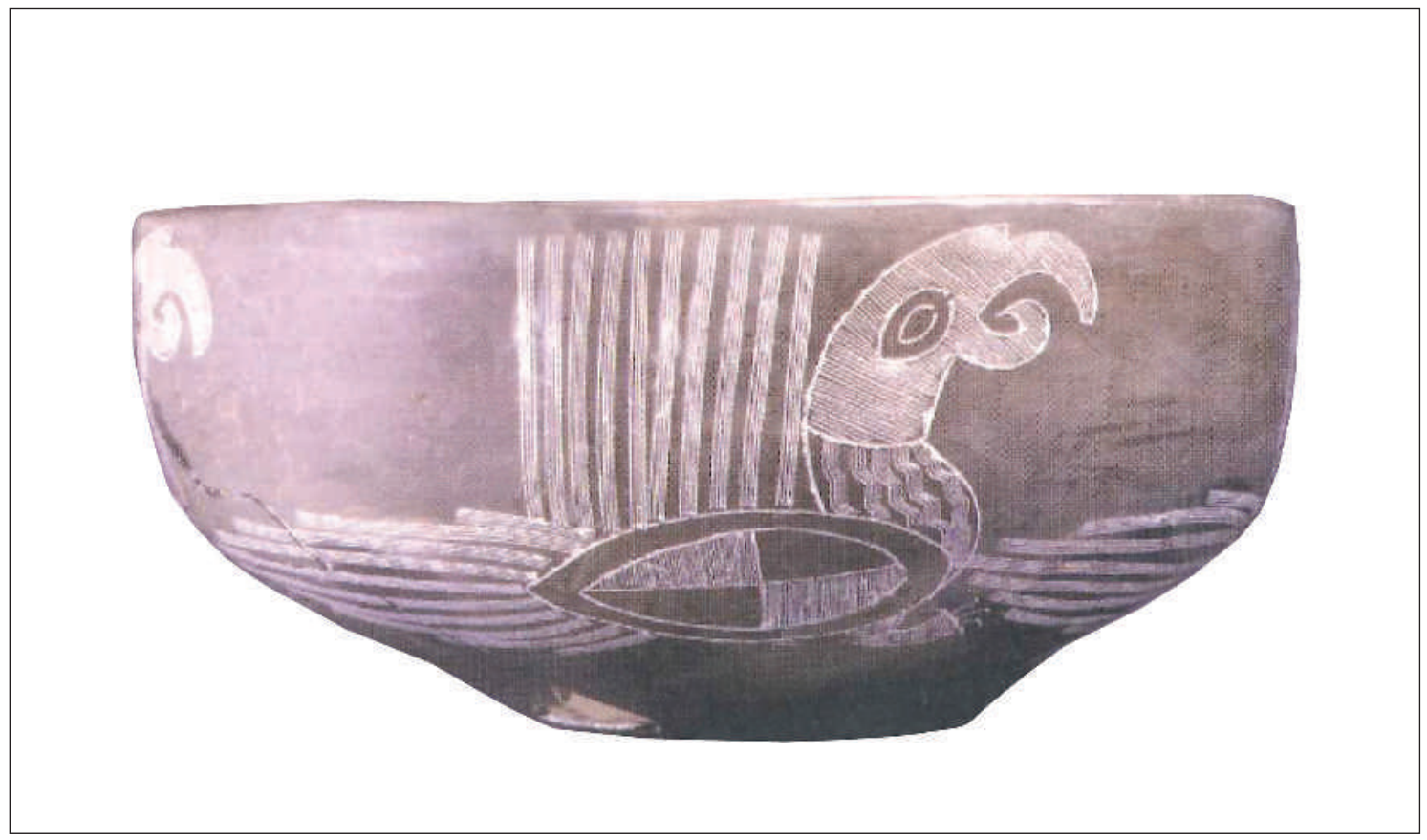

Figura 7. Representación en puco, estilo Hualfín Gris Grabado. Colección Muñiz Barreto, Museo de La Plata n 12.658 (apud González 1998: fig. 176). Figure 7. Ornithomorphic representation on a puco bowl in the Hualfin Gris Grabado style. Muñiz Barreto Collection, Museo de La Plata $n^{\circ} 12.658$ (apud González 1998: fig. 176.

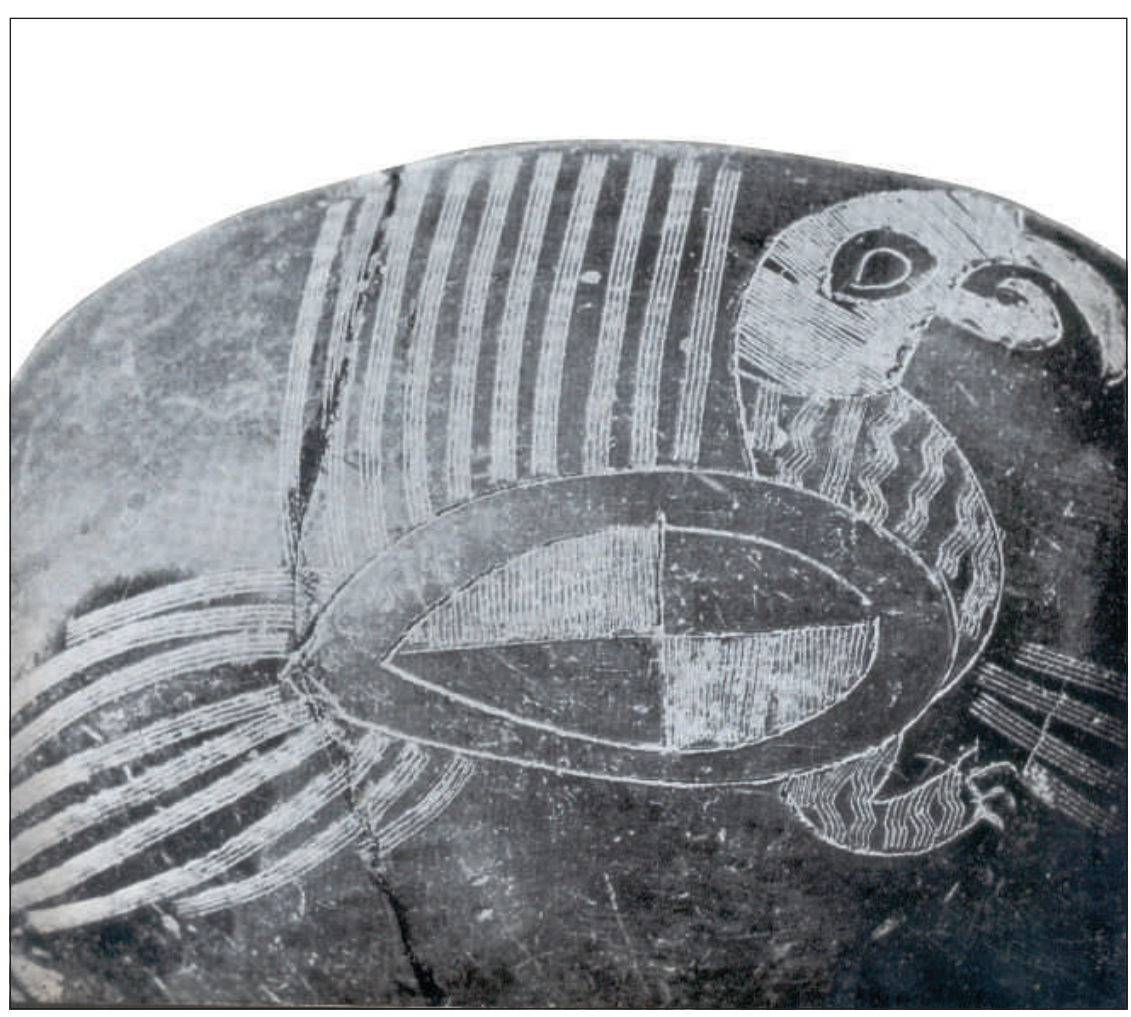

Figura 8. Otra de las representaciones del mismo puco de la fig. 7 (apud González 1977: fig. 135). Figure 8. Additional representations on the same puco bowl as in fig. 7 (apud González 1977: fig. 135). 


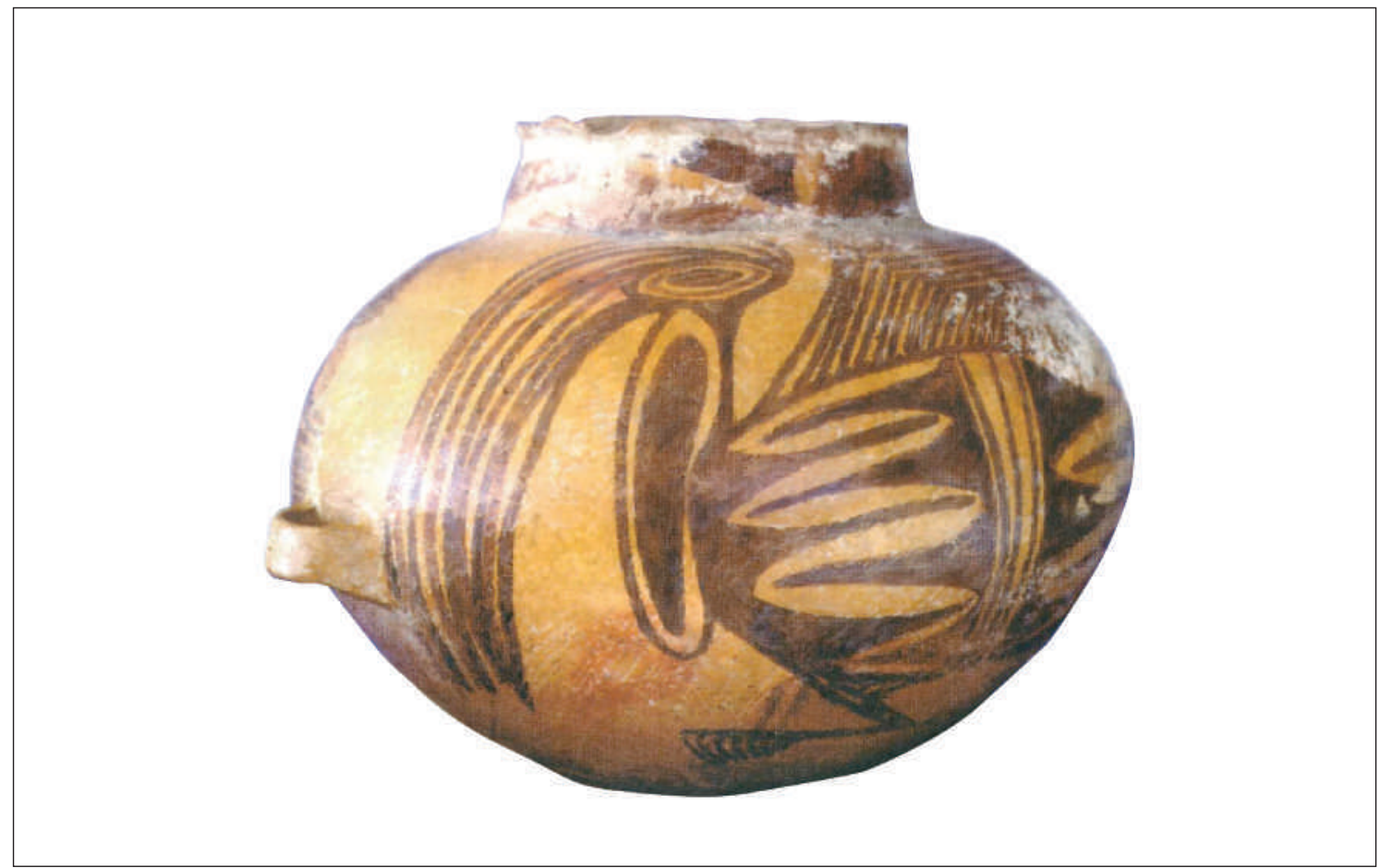

Figura 9. Representación ornitomorfa en vasija ovoide Aguada Pintado. Colección Museo Incahuasi (apud González 1998: fig. 205). Figure 9. Ornithomorphic representation on an oval-shaped Aguada Pintado vessel. Museo Incahuasi Collection (apud González 1998: fig. 205).

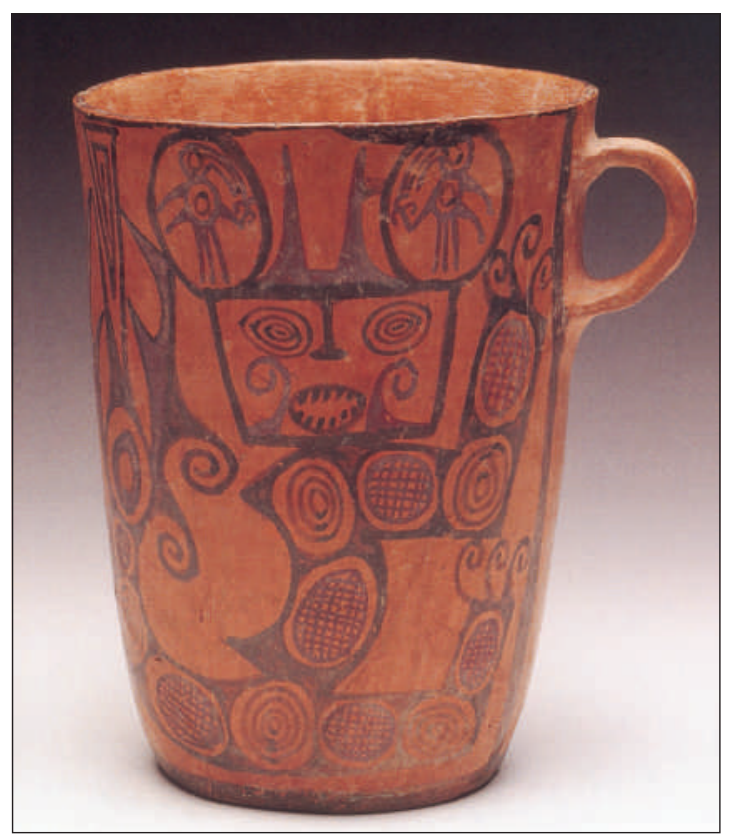

Figura 10. Vaso de cerámica Aguada pintado en negro y rojo. Colección Guido Di Tella no 8953 (apud Pérez Gollán 1994: 39). Figure 10. Ceramic Aguada cup painted in black and red. Guido Di Tella Collection nº 8953 (apud Pérez Gollán 1994: 39).

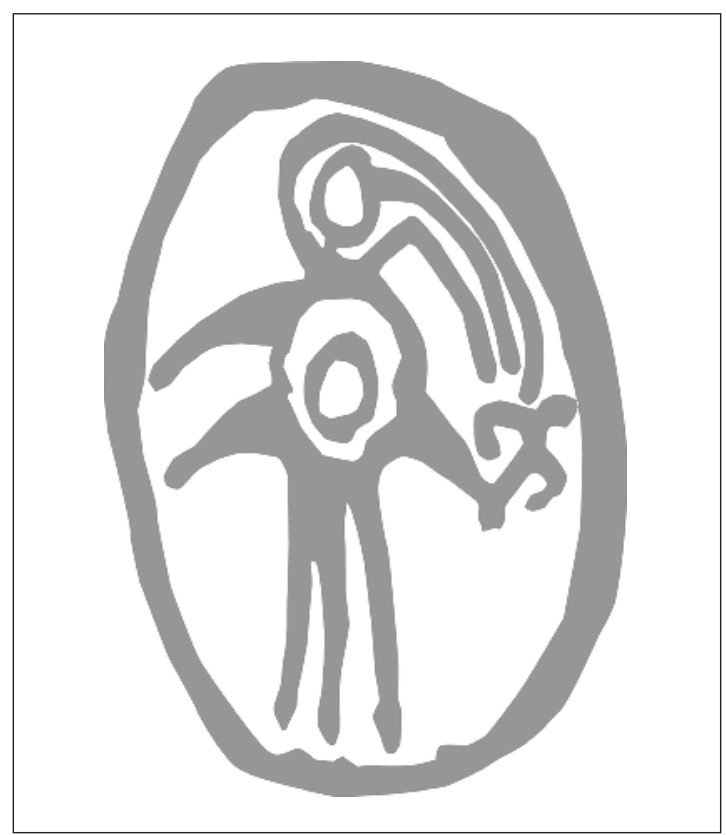

Figura 11. Detalle de la oreja izquierda de la figura 10. Figure 11. Detail of the left ear of the figure on the same cup as in fig. 10. 


\section{DISCUSIÓN}

A través de los efectos que las aves provocan en los humanos accedemos a aspectos importantes que comienzan a interaccionar en el juego de relaciones definidas al interior de la sociedad. A continuación exponemos la agencia desplegada entre persona/ambiente/ave/artefacto, intentando comprender el rol que jugaron las aves en la sociedad Aguada.

Atendiendo a las características y capacidades de las distintas aves representadas, podríamos considerarlas como observadas e influyentes sobre estos grupos humanos. Cuando analizamos las IMV, constatamos que la mayoría de las aves coincidían en su hábitat con la zona de recuperación de los objetos estudiados (valles).

Por otro lado, observamos un segundo caso representado por aves como Ara sp. y Ramphastos toco que habitan zonas selváticas como las yungas. En cuanto al primer caso, suponemos que la presencia de bandadas y nidos sería puntualmente conocida. El loro barranquero, por ejemplo, vive en sociedades grandes y el ruido que provoca, tanto en vuelo como en sus nidos, no pasaría desapercibido por los humanos. Su alimentación a base de semillas podría haber llevado a una intensa interacción entre unos y otros, como los robos de comida, teniendo en cuenta la capacidad productiva agrícola para el momento (en la actualidad, estos loros frecuentan campos de cultivos de maíz y trigo para aprovechar sus semillas). El ruido provocado por los loros sirve como alerta para saber cuándo se acercan. En el pasado, la llegada de estas aves podría actuar como índice de la madurez de los granos, debido a su relación de causalidad. La reacción de los agricultores ante su presencia nos es desconocida hasta el momento, quizás el asociar la cosecha con la presencia del loro barranquero hubiese dotado a la especie de algún signo de estatus especial, o significado vinculado a la fertilidad/abundancia.

Otro ejemplo de relación de causalidad objeto-signo entre un acontecimiento natural y el arribo de las aves, que deriva en un representamen similar al propuesto, es el caso de las parinas, consideradas un signo de fertilidad y prosperidad al migrar en la época de lluvias (Sigl \& Mendoza 2012). A esta interpretación debemos sumar el contraste de sus colores, como el verde, el amarillo y el rojo. Está documentado para momentos incas que el rojo se asocia a la sangre (Mignone 2009), mientras que el amarillo o dorado del oro se asocia a Inti, el Sol. Los motivos de la asociación no son arbitrarios, sino que se basan en la similitud de cualidades como el color. En este caso hablamos de una relación icónica de semejanza entre signo y objeto. Actualmente, en el altiplano boliviano, las plumas verdes de los psitácidos se utilizan como metáfora del florecimiento de los sembradíos de la papa en el atuendo plumario denominado llaqa (Jaimes Betancourt 2015). ${ }^{3}$ Si consideramos la hipótesis de González (2004), quien plantea una relación de Aguada con la cultura Tiwanaku, y esta como precursora del incario, podríamos considerar una perduración del significado de estos colores a lo largo del tiempo y el espacio, algo sobre lo cual haría falta profundizar.

El suri y el cóndor han sido las representaciones más atendidas en el ámbito arqueológico, debido a la evidente presencia en la zona de expansión Aguada. Sin embargo, la búsqueda de un significado no ha sido llevada a cabo con suficiente dedicación. En cuanto al cóndor

\footnotetext{
Este animal es el actor principal en muchos mitos de origen (de los productos agrícolas, la casa, matrimonios, etc.), posee el rango de deidad relacionada con el "reino del aire" o como espíritu tutelar de la casa y hasta adopta forma humana en algunos cuentos aymaras que explican las jerarquías sociales y estructuras familiares (Martel 2009: 55).
}

Las cualidades destacadas del cóndor estarían dadas por el vuelo, su contraste blanco-negro, su tamaño y su visión a grandes distancias. En la figura 5, la representación muestra un felino antropomorfizado. La asociación de cóndor y jaguar podría entenderse en contextos rituales chamánicos y, quizás, el rectángulo con incisiones que el cóndor posee en su espalda hace alusión a una tableta de rapé, documentadas en el NOA y asociadas a estos contextos.

Adán Quiroga (1901) ha vinculado las danzas de Rhea sp. en épocas de lluvias con el signo cruciforme que aparece frecuentemente en estas representaciones. El signo de la cruz representa el rayo y la lluvia (transversal) y las nubes o el viento (horizontal). El suri se convierte en signo específico y anunciador de lluvias o épocas fértiles. Su comportamiento se asocia por causalidad a un determinado estado atmosférico favorable para las comunidades agrícolas. En las figuras analizadas, el signo cruciforme no está representado, pero la figura 3 constituye un recipiente claramente asociado a lo líquido, por lo que la inclusión del ave en sí probablemente no sea casual. La figura 4 , correspondiente a una vasija que contenía un párvulo, pudo incluir al suri cordillerano como parte de su significado total, donde el difunto actúa como transmisor de un pedido de fertilidad o lluvias. 
En cuanto al falconiforme representado en la figura 2, al no poder identificarlo a nivel de especie ni género, solo podemos evaluar algunas cualidades generales de este orden, como su gran visión, su capacidad para la caza y su rol de predador. Posee un comportamiento defensivo en cuanto a la protección del alimento. Esta cuenta cumpliría quizás un rol protector o represente las propias cualidades o roles de quien lo usa, tal como una persona encargada de la defensa y cuidado, como un centinela. En este caso, la pieza sugeriría alguna cualidad vinculada al ave representada en el sujeto que la use, como la amplia visión otorgada por sus vuelos a gran altura y su capacidad de reaccionar ante posibles situaciones de peligro o de cacería. Para ilustrar un caso similar, entre los yuracarés, en Bolivia, se realiza una ceremonia de iniciación para los niños de ambos sexos denominada "sunchado", la cual consiste en cortar la parte inferior de los brazos con huesos de Geranospiza caerulescens (gavilán patas largas) para los hombres y punciones en las piernas para las mujeres. El ritual otorgaría a los niños "la puntería del águila" y a las niñas "su valentía" (Lewis 2016).

En Ara sp., destaca lo colorido de su plumaje, el tamaño de los individuos, del pico y la cola. Considerando que los guacamayos habitan zonas selváticas, es probable que la interacción entre ellos y los humanos se diera en los desplazamientos de estos últimos, quizás por motivos de intercambio. El tráfico entre valles-selva o puna-selva está documentado, por ejemplo, en trabajos como los de López Campeny et al. (2014), Aschero (2007). Probablemente el intercambio también haya incluido plumas de guacamayos. Su utilización en la elaboración de adornos cefálicos, piezas textiles u ofrendas rituales pudo haber sido uno de los fines de tal empresa. Se han documentado contextos vinculados al caravaneo en el período aquí tratado con ofrendas plumarias de psitácidos provenientes de las tierras bajas en el sitio Cueva Inca Viejo, en la puna salteña (López et al. 2015). De todas formas, una imagen del guacamayo que se repite tanto en vasos como diademas nos hace pensar que el animal en sí posee significado y no solo sus plumas. ${ }^{4}$

Es interesante recalcar la idea de magia contagiosa $o$ simpática de Frazer (1915), por la cual algo que estuvo en contacto con otra cosa o es semejante a la misma, puede continuar en comunicación con ella o generar lo que su semejante provoca. Actualmente, esto es ampliamente documentado en comunidades andinas y de yungas. Esta idea nos habla de la agencia de los animales y a la vez de los objetos. Nos encontramos frente a un objeto (diadema o vaso) que hace referencia a un existente real (atractor existencial): guacamayo, que a la vez es signo de vuelo, observación y comunicación; aspectos todos connotados por el ave (objeto) debido a sus relaciones de iconicidad y factorialidad con la misma. Así, el “....aspecto icónico [...] resulta evidente pero el uso y funcionalidad que podemos atribuirle, al menos hipotéticamente, [hace] que sobresalga el aspecto simbólico" (Martel \& Giraudo 2014: 34). En el caso de la diadema, podría ser de uso ornamental, se coloca en la cabeza, parte superior y por encima del cuerpo, aludiendo otra vez a la altura (vuelo). En cuanto al vaso, sirve para contener e ingerir algún producto, el cual podría incluir o transmitir capacidades únicas de los guacamayos, o permitir comunicarse con los mismos (ver mitos y ritos con relación a estos aspectos en Ottalagano 2007). Ambos objetos fueron elaborados para formar parte de contextos específicos, los cuales desconocemos, pero en el caso de haber sido utilizados, su portador quizás pudo, por transposición de cualidades, adquirir la capacidad de sobrevolar, escudriñar, escuchar y transmitir mensajes en la selva, tal como lo hace el ave. Lo anterior permite acercarnos al atractor simbólico planteado para la IMV, el cual se refiere al valor social que posee la misma. Sabemos que los objetos encontrados se hallan alejados del hábitat del guacamayo, pero su valor social fue lo suficientemente alto como para justificar su representación. Teniendo en cuenta esto y las cualidades del referente (guacamayo), podemos suponer que el vaso y la diadema implicaron un control que va más allá de los valles. En estos procesos participan humanos y no humanos interrelacionados en entramados con diferentes alcances, los que no tienen un inicio y un fin claros. Rescatamos esto para poder extender la comprensión del contexto hacia asociaciones que van más allá de la naturaleza física de los objetos. No se puede seguir pensando en el contexto como algo estático y limitado a distribuciones y asociaciones físicas en un espacio determinado (Laguens \& Pazzarelli 2011).

En cuanto a los Ramphastos sp., destacamos el tamaño de su pico, su color contrastante entre el blanco-negro y el rojo-amarillo, su vuelo rectilíneo, su posicionamiento en la altura, sus graznidos y el repiqueteo del pico. En la figura 10 , se representa un antropomorfo felinizado con dos discos que hacen de oreja donde se encuentran las IMV referidas a los tucanes. En varios trabajos se ha discutido la relación entre el jaguar y el hombre, asociándola a contextos chamánicos. ${ }^{5}$ Sin embargo, no es 
nuestra intención plantear una discusión alrededor de la presencia del felino en este contexto. Nuestro objetivo está puesto en el tucán. Llamazares \& Martínez (2006) hacen hincapié en cómo el chamán alcanza la conexión con otras dimensiones espacio-temporales a través del vuelo. ${ }^{6}$ En el norte de Chile, en el cementerio Topáter, existe registro de cabezas y alas de aves vinculadas con instrumentos musicales, hojas de coca y otros objetos que parecen vincularse a funciones chamánicas (Thomas et al. 1995); los autores interpretaron esta recurrente referencia a las aves como elementos auxiliares al trance del chamán y su comunicación con la esfera sobrenatural. En nuestro caso, como el tucán forma parte del cuerpo del jaguar, podemos pensar en una relación intrínseca entre ambos, actuando como índices de una práctica concreta, en este caso el chamanismo. El tucán implicaría una IMv que incita a obtener ciertas cualidades del mismo -como el vuelo rectilíneo- al ingerir alguna sustancia en el vaso en el que se encuentra representado (tal como sucede en el caso de los Ara sp.). Entre los vapidianas de Brasil, existe un mito en el cual el tucán se halla vinculado con un loro decolorado, por lo que quizás su estatus sea similar al de algunos psitácidos (Lévi Strauss 1971).

Asio stygius se caracteriza por su visión nocturna y su capacidad de caza en medio de la noche. Ha sido documentado etnográficamente como los búhos, y por su vuelo silencioso se le asocia con voces y personas del más allá (Arenas \& Porini 2009). Tales consideraciones podrían basarse en el perfecto desempeño de esta especie en un ambiente hostil para el humano: la oscuridad y la noche. La cuenta, en este caso, podría estar ligada a una persona que mantenga alguna relación particular con este animal o con el medio en cual se desempeña. Sin embargo, considerando que es una especie que se encuentra fuera de la región de valles, sorprende que se la represente. Ateniéndonos a esto, la interacción con este individuo sería mucho más distante. Quizás los lazos entre los grupos de valles y selva sea mucho mayor de lo que se piensa. Existen especies que comparten las mismas características mencionadas anteriormente y que se encuentran en la zona de valles. Dicho esto, ¿cómo explicamos que se elija esta y no a Tyto alba (lechuza de campanario) como integrante de un colgante? Podemos pensar que, además, este búho haría alusión a un espacio particular como las zonas de yungas y bosques, o tal vez su sonido, los ojos amarillos y orejas paradas, aspectos particulares de esta especie, pueden tener que ver con su elección para ser representado.

\section{CONCLUSIONES}

En Aguada, las representaciones ornitomorfas son más diversas de lo que se piensa. Lo que en un momento González identificó como una rapaz, en realidad demostraría ser un guacamayo y lo que se consideraba una "gran ave", podemos decir hoy que se trata de un tucán. Si bien no en todos los casos pudimos identificar la especie, logramos aproximarnos a un género u orden. Consideramos que la identificación taxonómica, en conjunción con la etología de las aves, brindó el principal soporte que apoya la interpretación de las IMv.

Teniendo en cuenta lo planteado por otros autores para el fenómeno Aguada, respecto de su organización social y cúltica, no contamos con suficiente información sobre la evidencia material y contextual debido a la falta de divulgación de los datos referentes a excavaciones en la zona de estudio. Por ello, no podemos adherirnos a una postura que incluya a las aves dentro del repertorio de entidades cuyo manejo estuvo limitado únicamente a cierto sector social. Desconocemos la jerarquía que estas recibieron con relación a los demás elementos constituyentes de la cosmovisión de la sociedad estudiada, pero reconocemos la importancia que tuvieron por su amplia representación, aunque más modesta que otros animales como, por ejemplo, los felinos.

En este caso, las aves estarían presentes en todos los ámbitos de su vida. Entre humanos/no humanos existieron intercambios de capacidades y una íntima comunicación, así como normas que trascienden la barrera de lo social y atienden a los roles de todos los individuos, respetándose unos a otros como parte de la misma dinámica natural/social.

Para finalizar, queremos recordar que, carecer de muchos datos contextuales y análisis específicos que brinden mayor información sobre los objetos y el grupo social estudiado, dificulta la posibilidad de enriquecer las interpretaciones sobre el pasado. Somos conscientes de estas limitaciones, pero consideramos que la búsqueda de un posible significado de las cosas no está vetada para la arqueología. Nuestro análisis abre una puerta a estudios posteriores que retomen los temas tratados para acercarnos poco a poco a las pasadas interpretaciones y representaciones del mundo. 


\section{NOTAS}

\author{
1 "Una cosa que está en lugar de otra a los ojos de alguien, \\ bajo ciertos aspectos o capacidades" (Preucel 2006: 54). \\ ${ }^{2}$ Los signos indiciales, según Peirce, son aquellos en los \\ cuales la relación establecida entre objeto y signo que lo re- \\ presenta está dada por contigüidad, causalidad y factoriali- \\ dad (Preucel 2006). \\ ${ }^{3}$ La metáfora es un tipo de signo icónico que establece \\ una relación de semejanza entre las cualidades del signo y las \\ características del objeto al que refiere. \\ ${ }^{4}$ En Mendoza se han hallado diademas de metal con \\ representaciones de psitácidos en contextos tardíos (Ibarra \\ Grasso 1967). \\ ${ }^{5}$ Pérez Gollán (2000), Gudemos (2002), Llamazares \& \\ Martínez (2006), etcétera. \\ ${ }^{6}$ De la misma manera que el jaguar hace referencia a otra \\ cara de la humanidad, Ottalagano (2007) menciona que las \\ aves también son entidades emparentadas con los humanos, \\ por ejemplo, como espíritus fundadores.
}

Reconocimientos A nuestros compañeros y director del CERAR, Diego Ortiz. Sin su ayuda no podríamos haber imaginado este trabajo. A Álvaro Martel, por sus consejos y dedicación a la hora de responder nuestras inquietudes. A Silvana Urquiza y Gabriel Miguez por su interés en nuestro trabajo. A Soledad Martínez por su aliento y guía en el camino de la arqueología. A nuestro querido amigo Roy Casañas. A nuestros padres, quienes confiaron en nosotros desde el primer momento.

\section{REFERENCIAS}

Arenas, P. \& Porini, G. 2009. Las aves en la vida de los tobas del oeste de Formosa, Argentina. Asunción: Tiempo de Historia.

Aschero, C. 2007. Íconos, huancas y complejidad en la puna sur argentina. En Producción y circulación prehispánicas de bienes en el sur andino, A. Nielsen, M. Rivolta, V. Seldes, M. Vázquez, \& P. Mercolli, Comps., pp.135-167. Córdoba: Brujas.

Ataliva, V. 2000. Nota sobre la dualidad en Aguada. Un caso de estudio: la túnica hallada en San Pedro de Atacama, Chile. Estudios Atacameños 20: 67-75. San Pedro de Atacama.

ВАвот, Р. 2016. Notas sobre la arqueología de las plantas en un desierto de altura. Cadernos do Lepaarq 13 (25): 333-365. Pelotas.

Berenguer, J. 1984. Hallazgos de La Aguada en San Pedro de Atacama. Norte de Chile. Gaceta Arqueológica Andina 12: 12-14. Lima.

Canevari, M. \& Vaccaro, O. 2007. Guía de mamíferos del sur de América del Sur. Buenos Aires: LOLA.
Contino, F. 1982. Aves del Noroeste Argentino. Salta: Secretaría de Estado de Asuntos Agrarios, Dirección General de Recursos Naturales Renovables.

Cruz, P. 2007. Hombres complejos y señores simples. Reflexiones en torno a los modelos de organización social desde la arqueología del valle de Ambato (Catamarca). En Procesos sociales prehispánicos en el sur andino. La vivienda, la comunidad y el territorio, A. Nielsen, M. Rivolta, V. Seldes, M. Vázquez, \& P. Mercolli, Comps., pp. 99-122. Córdoba: Brujas.

Del VAlle, C. 2008. Introducción a la biología y ecología de las psitácidas neotropicales. En Memorias de la Conferencia interna en medicina y aprovechamiento de fauna silvestre, exótica y no convencional 4 (1): 4-6. <https://www.revistas. veterinariosvs.org/index.php/cima/article/view/55/pdf> [consultado 22-07-2018].

Delfino, D. 2005. Entre la dispersión y la periferia, sentidos de presencias y lagunización de La Aguada. En La cultura de la Aguada y sus expresiones regionales, Secretaría de Ciencia y Tecnología, pp. 263-292. La Rioja: Universidad Nacional de La Rioja.

FRAZER, J. 1915. The golden bough: a study in magic and religion. Londres: McMillan.

GonZÁLEZ, A. 1964. La cultura de la Aguada del N.O. Argentino. Revista del Instituto de Antropología 2-3: 205-253. Córdoba.

González, A. 1977. Arte precolombino de la Argentina, introducción a su historia cultural. Buenos Aires: Filmediciones Valero.

González, A. 1998. Arte precolombino. Cultura La Aguada, arqueología y diseños. Buenos Aires: Filmediciones Valero.

GonzÁlez, A. 2004. La arqueología del Noroeste Argentino y las culturas formativas de la cuenca del Titicaca. Relaciones de la Sociedad Argentina de Antropología 29: 7-38. Buenos Aires.

González, L. 2002. A sangre y fuego: nuevos datos sobre la metalurgia Aguada. Estudios Atacameños 24: 21-37. San Pedro de Atacama.

Gordillo, I., BALdini, M. \& Kusch, M. 2000. Entre objetos, rocas y cuevas: significados y relaciones entre la iconografía rupestre y mobiliar de Aguada. En Arte en las rocas: arte rupestre, menhires y piedras de colores en Argentina, M. Podestá \& M. de Hoyos, Eds., pp. 101-111. Buenos Aires: Sociedad Argentina de Antropología.

Gordillo, I. 2004. Arquitectos del rito: la construcción del espacio público en La Rinconada, Catamarca. Relaciones de la Sociedad Argentina de Antropología 29: 111-136. Buenos Aires.

Gudemos, M. 2002. ¿Una danza de integración regional en las pinturas rupestres de La Salamanca? Revista española de Antropología Americana 33: 83-119. Madrid.

IBARRA, D. 1967. Argentina indígena y prehistoria americana. Buenos Aires: Tipográfica Editora Argentina.

Jaimes, C. 2015. El poder de las plumas. Colección de arte plumario del Museo Nacional de Etnografía y Folklore, según la cadena de producción. La Paz: MUSEF. 
KNAPPET, C. 2008. The neglected networks of material agency: artefacts, pictures and texts. En Material agency, C. Knappet \& L. Malafouris, Eds., pp. 139-156. Boston: Springer-Verlag.

Korstanje, A. 1988. Aguada. Contribución al estudio de una compleja iconografía. Tesis para optar por el título de Licenciada en Historia, Facultad de Filosofía y Letras, Universidad de Tucumán.

Kusch, M. 1991. Forma, diseño y figuración en la cerámica pintada y grabada de la Aguada. El Arte rupestre en la Arqueología contemporánea, M. Podestá, M. Hernández \& S. Renard de Coquet, Eds., pp. 14-24. Buenos Aires: M. M. Podestá.

Kusch, M. 2000. Coincidencias y diferencias. La cerámica Portezuelo y el arte rupestre de Catamarca. En Arte en las rocas: arte rupestre, menhires y piedras de colores en Argentina, M. Podestá \& M. de Hoyos, Eds., pp. 95-100. Buenos Aires: Sociedad Argentina de Antropología.

Laguens, A. 2004. Arqueología de la diferenciación social en el valle de Ambato, Catamarca, Argentina (s. II-VI DC): el actualismo como metodología de análisis. Relaciones de la Sociedad Argentina de Antropología 29: 137-162. Buenos Aires.

Laguens, A. \& Pazzarelli, F. 2011. ¿Manufactura, uso y descarte? O acerca del entramado social de los objetos cerámicos. Museo de Antropología (4): 113-126. Córdoba.

LAW, J. 2008. The actor-enacted: cumbrian sheep in 2001. En Material Agency, C. Knappet \& L. Malafouris, Eds., pp. 57-77. Boston: Springer-Verlag.

LEwIs, R. 2016. Panorama etnográfico de los tres grupos étnicos del Trópico de Cochabamba (Yuracarés-Trinitarios-Yuquis) con relación a las aves. La Paz: CimA.

LÉvi-Strauss, C. 1971. De la miel a las cenizas. México DF: Fondo de Cultura Económica.

Llagostera, A. 1995. El componente cultural Aguada en San Pedro de Atacama. Boletín del Museo Chileno de Arte Precolombino 6: 9-34. Santiago.

Llamazares, A. \& Martínez, C. 2006. Reflejos de la cosmovisión andina. Arte indígena y chamanismo en el Noroeste Argentino prehispánico. En Tesoros precolombinos del Noroeste, M. Goretti \& L. González, Eds., pp. 63-91. Buenos Aires: Fundación CEPPA.

López, G., Coloca, F., Araya, S., Orsi, J. \& Seguí, S. 2015. El sitio Cueva Inca Viejo, salar de Ratones, puna de Salta: evidencia arqueológica y procesos de interacción macrorregional. Relaciones de la Sociedad Argentina de Antropología 40: 45-71. Buenos Aires.

López Campeny, S., Romano, A., Rodríguez, M., Martel, Á. \& Corbalán, M. 2014. De aquí y de allá: análisis integral de un contexto funerario. Vínculos e interacciones sociales entre puna meridional y tierras bajas orientales. Intersecciones en Antropología 15 (1): 201-218. Buenos Aires.

Magariños de Morentín, J. 2008. La semiótica de los bordes. Apuntes para una metodología semiótica. Córdoba: Comunic-Arte.
Manasse, B. 2000. La región pedemontana del sudoeste de la Provincia de Tucumán: Dptos. Alberdi y La Cocha. Shincal 6: 141-152. Catamarca.

MARTEL, Á. 2009. Pastores, cóndores y ofrendas: la ritualidad pastoril vista desde el arte rupestre del Valle Encantado (departamento San Carlos, Salta). Estudios AntropologíaHistoria Nueva Serie (1): 43-61. Buenos Aires.

Martel, Á. \& Giraudo, S. 2014. Semiótica de la imagen en arqueología: el caso de los "escutiformes". Revista Chilena de Antropología Visual 24: 21-45. Santiago.

Mignone, P. 2009. Miniaturas zoomorfas del volcán Llullaillaco y contraste entre régimen estatal y vida comunitaria en la Capacocha. Boletín del Museo Chileno de Arte Precolombino 14 (1): 55-68. Santiago.

Miguez, G., Nasif, N., Gudemos, M. \& Bertelli, S. 2013. Aves, sonidos y chamanes. Estudio interdisciplinario de un instrumento musical óseo procedente de una ocupación prehispánica de las selvas meridionales del noroeste de Argentina. Anales del Museo de América xxi: 174-193. Madrid.

Narosky, T. \& Yzurieta, D. 2010. Guía para la identificación de las aves de Argentina y Uruguay. Buenos Aires: Vázquez Mazzini.

Nasif, N. \& Miguez, G. 2014. La fauna relacionada en una comunidad prehispánica del piedemonte meridional de la provincia de Tucumán (Argentina). Folia Histórica del Noroeste 22: 203-232. Corrientes.

Nazar, C., De la Fuente, G. \& Gheco, L. 2014. Entre cebiles, cuevas y pinturas. Una mirada a la estética antropomorfa del arte rupestre de La Tunita, Catamarca, Argentina. Boletín del Museo Chileno de Arte Precolombino 19 (1): 37-51. Santiago.

Nazar, C., Gheco, L. \& Barot, A. 2012. Avances en la documentación del sitio La Tunita (Catamarca, Argentina). Comechingonia 16 (1): 315-325. Córdoba.

Oliszewski, N. 2004. Estado actual de las investigaciones arqueobotánicas en sociedades agroalfareras del área valliserrana del Noroeste Argentino (0-600 DC). Relaciones de la Sociedad Argentina de Antropología 29: 211-227. Buenos Aires.

Ottalagano, F. 2007. Algunas referencias en torno al simbolismo de las aves en los registros etnohistóricos y etnográficos de Guaycurúes y Mataco-Mataguayos. Arqueología Suramericana 3 (2): 213-228. Catamarca.

Ottalagano, F. 2008. Hacia la identificación taxonómica de las representaciones de psitácidos en la cerámica de la cuenca del río Paraná. Comechingonia 11: 79-98. Córdoba.

Pantorilla, M. \& Núñez Regueiro, V. 2006. Investigaciones arqueológicas en la zona de Escaba, Provincia de Tucumán: asentamientos Condorhuasi y Aguada de las Yungas. Intersecciones en Antropología 7: 235-245. Buenos Aires.

Pérez Gollán, J. 1991. La cultura de La Aguada vista desde el valle de Ambato. Publicaciones del CIFFYн 46: 47-99. Córdoba. 
Pérez Gollán, J. 1994. Los sueños del jaguar. Imágenes de la puna y la selva. Santiago: Museo Chileno de Arte Precolombino.

PÉrez Gollán, J. 2000. El jaguar en llamas: la religión en el antiguo Noroeste Argentino. En Nueva historia argentina. Los pueblos originarios y la conquista, M. Tarragó, Ed., pp. 229-257. Buenos Aires: Sudamericana.

Pontussi, P., Mármol, A., Argañaraz, R. \& Pontussi de RODRíGUEZ, M. 1995. Geografía del Noroeste Argentino. Salta: Universidad Nacional de Salta, Facultad de Cs. Naturales.

Preucel, R. 2006. Archaeological semiotics. Blackwell: Oxford.

Quiroga, A. 1901. La cruz en América. Buenos Aires: Imprenta y lithografía La Buenos Aires.

Rodríguez Mata, J., Erize, F. \& Bumboll, M. 2006. Guía de campo Collins. Aves de Sudamérica. Buenos Aires: Letemendia.
Sigl, E. \& Mendoza salazar, D. 2012. No se baila así nomás. Tomo I: poder, política, género, etnicidad, clase, religión y biodiversidad en las danzas del altiplano boliviano. Tesis para optar al grado de Doctora en Antropología Cultural y Social, Universidad Católica Boliviana San Pablo, La Paz-Bolivia.

Tartusi, M. \& NúÑEz Regueiro, V. 1990. Aproximación al estudio del área pedemontana de Sudamérica. Cuadernos del INA 12: 125-160. Buenos Aires.

TARTUSi, M. \& NúÑEZ REgueiro, V. 2002. Aguada y el proceso de integración regional. Estudios Atacameños 24: 9-19. San Pedro de Atacama.

Thomas, C., Benavente, M., Cartagena, I. \& Serracino, G. 1995. Topáter, un cementerio temprano: una aproximación simbólica. Actas del XIII Congreso Nacional de Arqueología Chilena, volumen 2, pp. 159-173. Antofagasta.

YACOVLEFF, E. 1932. Las falcónidas en el arte y en las creencias de los antiguos peruanos. Revista del Museo Nacional 1 (1): 33-111. Lima. 